\title{
Deletion of a non-canonical regulatory sequence causes loss of Scn1a expression and epileptic phenotypes in mice
}

Jessica L. Haigh ${ }^{1,2 \dagger}$, Anna Adhikari ${ }^{1,3 \dagger}$, Nycole A. Copping ${ }^{1,3}$, Tyler Stradleigh ${ }^{1,2}$, A. Ayanna Wade ${ }^{1,2}$, Rinaldo Catta-Preta ${ }^{1,2}$, Linda Su-Feher ${ }^{1,2}$, Iva Zdilar ${ }^{1,2}$, Sarah Morse ${ }^{1,2}$, Timothy A. Fenton ${ }^{1,3}$, Anh Nguyen ${ }^{1,2}$, Diana Quintero ${ }^{1,2}$, Samrawit Agezew ${ }^{1,2}$, Michael Sramek ${ }^{1,2}$, Ellie J. Kreun ${ }^{1,2}$, Jasmine Carter ${ }^{1,2}$, Andrea Gompers ${ }^{1,2}$, Jason T. Lambert ${ }^{1,2}$, Cesar P. Canales ${ }^{1,2}$, Len A. Pennacchio ${ }^{4,5,6}$, Axel Visel ${ }^{4,5,6,7}$, Diane E. Dickel ${ }^{4,5,6}$, Jill L. Silverman ${ }^{1,3^{*}}$ and Alex S. Nord ${ }^{1,2^{*}}$ (D)

\begin{abstract}
Background: Genes with multiple co-active promoters appear common in brain, yet little is known about functional requirements for these potentially redundant genomic regulatory elements. SCN1A, which encodes the Nav1.1 sodium channel alpha subunit, is one such gene with two co-active promoters. Mutations in SCN1A are associated with epilepsy, including Dravet syndrome (DS). The majority of DS patients harbor coding mutations causing SCNIA haploinsufficiency; however, putative causal non-coding promoter mutations have been identified.
\end{abstract}

Methods: To determine the functional role of one of these potentially redundant Scn1a promoters, we focused on the non-coding $\operatorname{Scn} 1 \mathrm{a} 1 \mathrm{~b}$ regulatory region, previously described as a non-canonical alternative transcriptional start site. We generated a transgenic mouse line with deletion of the extended evolutionarily conserved $1 \mathrm{~b}$ non-coding interval and characterized changes in gene and protein expression, and assessed seizure activity and alterations in behavior.

Results: Mice harboring a deletion of the $1 \mathrm{~b}$ non-coding interval exhibited surprisingly severe reductions of $\operatorname{Scn} 1 a$ and Nav1.1 expression throughout the brain. This was accompanied by electroencephalographic and thermalevoked seizures, and behavioral deficits.

Conclusions: This work contributes to functional dissection of the regulatory wiring of a major epilepsy risk gene, SCN1A. We identified the $1 \mathrm{~b}$ region as a critical disease-relevant regulatory element and provide evidence that noncanonical and seemingly redundant promoters can have essential function.

\footnotetext{
* Correspondence: jsilverman@ucdavis.edu; asnord@ucdavis.edu

${ }^{\dagger}$ Jessica L. Haigh and Anna Adhikari contributed equally to this work.

${ }^{1}$ Department of Psychiatry and Behavioral Sciences, University of California,

Davis, Davis, CA, USA

Full list of author information is available at the end of the article
}

C C The Author(s). 2021 Open Access This article is licensed under a Creative Commons Attribution 4.0 International License, which permits use, sharing, adaptation, distribution and reproduction in any medium or format, as long as you give appropriate credit to the original author(s) and the source, provide a link to the Creative Commons licence, and indicate if changes were made. The images or other third party material in this article are included in the article's Creative Commons licence, unless indicated otherwise in a credit line to the material. If material is not included in the article's Creative Commons licence and your intended use is not permitted by statutory regulation or exceeds the permitted use, you will need to obtain permission directly from the copyright holder. To view a copy of this licence, visit http://creativecommons.org/licenses/by/4.0/. The Creative Commons Public Domain Dedication waiver (http://creativecommons.org/publicdomain/zero/1.0/) applies to the data made available in this article, unless otherwise stated in a credit line to the data. 


\section{Background}

A large proportion of brain-expressed and, indeed, all mammalian genes are believed to rely on multiple alternative promoters [1-3]. For many genes, the alternative promoters produce distinct $5^{\prime}$ untranslated regions but otherwise similar mRNA products, leading to identical proteins from distinct transcription start sites (TSSs) [4, 5]. Much of the focus on understanding the role of alternative promoters in mammalian transcriptional regulation has been on the potential for discrete function via producing specific isoforms or compartmentalized expression in specific cells or tissues [6-9]. However, TSS activity mapping has found many genes where alternative promoters are also active in the same tissue $[10,11]$. More recent evidence from single-cell RNA sequencing and chromosome conformation suggests that annotated alternative promoters are frequently co-active in the same cells and physically interact in the nucleus [1214]. However, in contrast to work on the requirement for alternative promoters with presumed discrete activity, studies investigating the functional requirement for apparently redundant co-active promoters are lacking.

Epilepsy is one of the most common neurological disorders, with both rare highly penetrant and common variants contributing to genetic etiology. Mutations in SCN1A, which encodes the $\mathrm{Na}_{\mathrm{V}} 1.1$ sodium channel alpha subunit, result in a range of epilepsy phenotypes from generalized febrile seizures to Dravet syndrome (DS), a severe childhood-onset disorder [15-17]. The majority of DS cases are caused by heterozygous de novo mutations in SCN1A resulting in truncation of the protein, with haploinsufficiency of $\mathrm{Na}_{\mathrm{V}} 1.1$ presumed to underlie pathology $[18,19]$. Mouse models with heterozygous coding mutations in $S c n 1 a$ recapitulate features of DS, including seizures and sudden unexpected death in epilepsy (SUDEP) [20-26]. DS remains pharmacoresistant, with generalized tonic-clonic seizures beginning in the first year of life and common comorbid neurodevelopmental disorder (NDD) behavioral phenotypes including cognitive impairments and ataxia [27-29].

SCN1A transcripts have a variable $5^{\prime}$ untranslated region (UTR) containing one of two TSSs, $1 \mathrm{a}$ and $1 \mathrm{~b}$, that are conserved between human and mouse [30, 31]. The proteins produced from $1 \mathrm{a}$ and $1 \mathrm{~b}$ are expected to be identical. 1a was found to be the majority TSS for SCN1A transcripts across human and mouse $(54 \%$ and $52 \%$ RACE transcripts, respectively). No strong regionspecific differences in 1a versus $1 \mathrm{~b}$ TSS usage across brain regions have been identified in previous work [30, 32]. 1a (also referred to as $\mathrm{h} 1 \mathrm{u}$ ) has been defined as the major SCN1A promoter; however, comparison across brain tissues in human and mouse suggests that 1a and $1 \mathrm{~b}$ are co-active, with $\sim 35 \%$ of transcripts arising from $1 \mathrm{~b}$ [30]. The apparent functional redundancy of $1 \mathrm{a}$ and 1b promoter activity and 1a- and 1b-associated SCN1A transcripts raises the question of whether there are distinct roles or requirements of the $1 \mathrm{a}$ and $1 \mathrm{~b}$ UTR and regulatory DNA sequences.

In addition to serving as an example in which to dissect the role of multiple co-active promoters, there is significant disease relevance for understanding the functional requirements for $S C N 1 A$ regulatory DNA elements. SCN1A is one of the most common and welldocumented genes associated with severe medical consequences of haploinsufficiency. Further, genome-wide association studies (GWAS) have implicated non-coding SCN1A DNA variants as contributing to epilepsy risk [33, 34], presumably via more subtle perturbation to transcriptional regulation, and non-coding promoter deletions have been found in DS patients [35, 36]. A recent study of common variation in the promoter regions of $S C N 1 A$ found that promoter variant haplotypes reduced luciferase in cells and that such non-coding variants in the functional SCN1A allele may modify DS severity [37]. Based on these findings, it is plausible that pathogenic variation in regulatory regions modulates SCN1A transcription, contributing to epilepsy. Functional studies are needed to determine the consequences of perturbations to SCN1A expression caused by mutations in non-coding DNA.

Here, we investigate $S c n 1 a$ as a model for examining transcriptional and phenotypic consequences associated with loss of a potentially redundant co-active promoter. Combining genomics, neuropathology, behavior, seizure susceptibility, and EEG, we show that the Scn1a 1b noncanonical promoter and flanking conserved non-coding DNA sequence is independently essential for expression and brain function via characterizing the impact of deletion in $1 \mathrm{~b}^{+/-}$and $1 \mathrm{~b}^{-/-}$mice. In addition to mapping an essential regulatory region of a critical disease-relevant gene, our findings provide evidence that non-canonical promoters can play essential roles in general transcriptional activation.

\section{Methods}

\section{Analysis of existing datasets}

Chromosome conformation (Hi-C), histone posttranslational modification (PTM), ChIP-seq, and chromatin accessibility (ATAC-seq) analyses were performed using published data. For human brain, chromatin contacts were displayed as a heatmap of pseudo-log contact matrix scores obtained at $10-\mathrm{kb}$ resolution from the PsychEncode.org resource website [38]. Differential Hi-C comparisons were conducted with contact matrices at 40-kb resolution for prefrontal cortex (PFC), right ventricle, hippocampus, lung, and pancreas with data obtained from Schmitt et al. [39], NCBI Gene Expression Omnibus (GEO) dataset GSE87112. The heatmaps for 
individual tissues were generated with the pseudo-log of the scores in the contact matrices, while the inter-tissue comparisons were composed with the log likelihood of scores of one tissue against each other. Frontal lobe histone PTMs were assessed using ChIP-seq coverage from the Roadmap Epigenomics Consortium [40] as integrated in the UCSC Genome Browser [41], data available at https://egg2.wustl.edu/roadmap/web_portal/. Assessment of chromatin accessibility for dorsolateral PFC neuronal and non-neuronal ATAC-seq data was made in the same way with data from Fullard et al. [42], GSE96949. For mouse brain, assessment of chromatin accessibility was performed using ATAC-seq data from purified excitatory, and parvalbumin (PV) and vasoactive intestinal peptide (VIP) expressing neurons obtained from Mo et al. [43], GSE63137.

\section{Generation of $1 \mathrm{~b}$ mutant mice}

We used Cas9-mediated mutagenesis of C56BL/6N oocytes to generate a mouse line harboring deletion of a conserved portion on the non-coding region of Scnla containing the previously described $1 \mathrm{~b}$ [30] regulatory region. Guide RNA was designed and synthesized according to described methods [44], pooled with Cas9 mRNA and injected into mouse oocytes. The gRNA sequences were GGAGATCTGGGTAGTCCTCG and GCTTTTCATACTATAGTGAG. Initial Cas9 targeting was performed at Lawrence Berkeley National Laboratory. F0s (induced on C57BL/6N background) carrying mutations were genotyped and bred to expand a line harboring a 3063-bp deletion at the $1 \mathrm{~b}$ interval (mm10 chr2:66407567-66410630).

The colony was rederived and maintained by crossing male $1 \mathrm{~b}$ deletion carriers with $\mathrm{C} 57 \mathrm{BL} / 6 \mathrm{~N}$ wildtype females (Charles River). Extensive crossing of heterozygous mutation carriers to wildtype animals vastly reduces the likelihood that any potential off-target mutations caused by Cas 9 targeting would persist in our $1 \mathrm{~b}$ deletion line. Genotypes were identified via PCR and sequence-verified for all animals included in analyses, with the primers in Table 1. All mouse studies were approved by the Institutional Animal Care and Use Committees at the University of California Davis and the Lawrence Berkeley National Laboratory. Mice were housed in a temperature-controlled vivarium maintained on a 12-h light-dark cycle. Efforts were made to minimize pain and distress and the number of animals

Table $1 \mathrm{Scn} 1 \mathrm{a} 1 \mathrm{~b}$ deletion genotyping primers

\begin{tabular}{ll}
\hline Primer name & Sequence (5'-3') \\
\hline L_outer_Scn1a & AGATCAGGCCTTCTTGCTGA \\
R_outer_Scn1a & GGGCTCCTCATTGTTTTGGG \\
R_interal_Scn1a & CACACACAGGCACATGATGA \\
\hline
\end{tabular}

used. Survival was monitored and log-rank Mantel Cox used to assess survival rate.

Table 2 summarizes the sex, genotype, age, and $n$ for each experiment.

\section{RNA collection}

Cortex, hippocampus, and cerebellum were regionally dissected from one hemisphere of P7, P32, and 3month-old homozygous deletion, heterozygous, and wildtype mice following anesthesia with isoflurane and decapitation. The other hemisphere was used for Western blot analysis. Both male and female mice were used, though there was no equal sex representation across genotypes. Total RNA was isolated using RNAqueous kit (Ambion) and assayed using an Agilent BioAnalyzer instrument.

\section{qRT-PCR}

Differential expression of Scn1a was verified by qRTPCR at 3 months old. Primers are reported in Table 3, and $\mathrm{qPCR}$ was performed with SYBR green PCR master mix (Applied Biosystems). Samples were excluded if technical replicates failed. Cycle counts were normalized to Gapdh. Statistical analysis was performed using ANOVA followed by Tukey's on relative gene expression between genotypes using $\Delta \Delta \mathrm{CT}$.

\section{RNA-seq}

RNA from P7 forebrain and P32 hippocampus was collected as described above. Samples included males and females of each genotype when possible. Stranded mRNA sequencing libraries were prepared using TruSeq Stranded mRNA kits (Illumina). Each round of sequencing was quantified, pooled, and sequenced in one lane on the Illumina HiSeq platform using a single-end 50-bp (P7, P32 homozygous) or paired-end 150 (P32 heterozygous) strategy at the UC Davis DNA Technologies Core.

The transcriptomic analysis was performed as before [45]. Reads from RNA-seq were aligned to the mouse genome (mm9) using STAR (version 2.7.2) [46]. Aligned reads mapping to genes were counted at the gene level using subreads featureCounts [47]. The mm9 knownGene annotation track and aligned reads were used to generate quality control information using the full $\mathrm{RSeQC}$ tool suite [48]. Unaligned reads were quality checked using FastQC.

\section{Differential expression analysis}

Raw count data for all samples were used for differential expression analysis using edgeR [49]. Genes with at least 1 read per million in at least one sample were included for analysis, resulting in a final set of 15589,14631 , and 15002 genes for differential testing in P7 and P32 mice, respectively. Multidimensional scaling analysis indicated 
Table 2 Sex, genotype, age, and $n$ for each experiment

\begin{tabular}{llll}
\hline Experiment & $\boldsymbol{n}$ & Region & Age \\
\hline qPCR & $\mathrm{WT}=4 \mathrm{~F}, 1 \mathrm{~b}^{+/-}=5(4 \mathrm{~F}, 1 \mathrm{M}), 1 \mathrm{~b}^{-/-}=7(2 \mathrm{~F}, 5 \mathrm{M})$ & $\begin{array}{l}\text { Cortex } \\
\text { Hippocampus } \\
\text { Cerebellum }\end{array}$ \\
Western blot & $\mathrm{WT}=3 \mathrm{M}, 1 \mathrm{~b}^{+/-}=3 \mathrm{M}, 1 \mathrm{~b}^{-/-}=3 \mathrm{M}$ & $\begin{array}{l}\text { Cortex } \\
\text { Hippocampus } \\
\text { Cerebellum }\end{array}$ \\
IF & $\mathrm{WT}=3,1 \mathrm{~b}^{+/-}=3,1 \mathrm{~b}^{-/-}=3$ & Brain & $\mathrm{P} 29-\mathrm{P} 32$ \\
RNA-seq & $\mathrm{WT}=2 \mathrm{M}, 1 \mathrm{~b}^{+/-}=4(2 \mathrm{M}, 2 \mathrm{~F}), 1 \mathrm{~b}^{-/-}=2 \mathrm{~F}$ & Forebrain & $\mathrm{P} 7$ \\
Behavior & $\mathrm{WT}=2 \mathrm{~F}, 1 \mathrm{~b}^{-/-}=2(1 \mathrm{M}, 1 \mathrm{~F}) ; \mathrm{WT}=3 \mathrm{M}, 1 \mathrm{~b}^{+/-}=4(3 \mathrm{M}, 1 \mathrm{~F})$ & Hippocampus & $\mathrm{P} 32$ \\
Thermal-induced seizures & $\mathrm{WT}=26(12 \mathrm{M}, 14 \mathrm{~F}), 1 \mathrm{~b}^{+/-}=30(15 \mathrm{M}, 15 \mathrm{~F}), 1 \mathrm{~b}^{-/-}=12(6 \mathrm{M}, 6 \mathrm{~F})$ & & Started at 6 weeks \\
\hline
\end{tabular}

that $\operatorname{Scn} 1 a$ expression and sex were the strongest driver of variance across samples. Tagwise dispersion estimates were generated and differential expression analysis was performed using a generalized linear model with genotype as the variable for testing. Effect of genotype was modeled as individual comparison of heterozygous and homozygous $1 \mathrm{~b}$ deletion mice with the respective WT controls. Normalized expression levels were generated using the edgeR pseudocount and rpkm functions. Aligned reads contained in BAM files from each sample were counted to calculate the overlap of sequencing reads with each locus. The coordinates for each locus were $\mathrm{m} 1 \mathrm{a}$ : chr2:66,278,753-66,278,887, the m1b deletion region: chr2:66245632-66248697, and m1c: chr2:66,249, 400-66,249,514. Mouse gene ontology (GO) data was downloaded from Bioconductor (org. Mm.eg.db). We used the goseq package to test for enrichment of GO terms indicating parent:child relationships. For GO analysis, we examined down- and upregulated genes separately for genes meeting an $\mathrm{FDR}<0.05$. For the enrichment analysis, the test set of differentially expressed genes was compared against the background set of genes expressed in our study.

\section{Immunofluorescence}

All histological experiments were performed at least in triplicate and experimenters were blinded to genotype. Following anesthesia with isoflurane, P28 male and female mice were transcardially perfused with $4 \%$

Table 3 qPCR primers

\begin{tabular}{ll}
\hline Target & Sequence $\left(\mathbf{5}^{\prime} \mathbf{-} \mathbf{3}^{\prime}\right.$ ) \\
\hline Human Gapdh & F-CAATGACCCCTTCATTGACC \\
Mouse Gapdh & R-TTGATTTGGAGGGATCTCG \\
& F-TCACCACCATGGAGAAGGC \\
Scnla (mouse and human) & R-GCTAAGCAGTTGGGGTGCA \\
& F-CTCGTTCCTGATCGTGTTCC \\
& R-ATCCTGTCCACAGCAATCTG \\
\hline
\end{tabular}

paraformaldehyde (PFA) in HEPES, followed by overnight fixation in the same solution. After fixation, brains were removed from the skull, embedded in 2\% LTE agarose/ Tris-buffered saline (TBS) and cut coronally in $50-\mu \mathrm{m}$ sections on a vibratome (VT 1000S, Leica). Sections underwent antigen retrieval in a solution of $0.1 \mathrm{M}$ sodium citrate ( $\mathrm{pH} \mathrm{6)}, 200 \mathrm{mM}$ sucrose, and 1\% (v/v) hydrogen peroxide at $60^{\circ} \mathrm{C}$ for $1 \mathrm{~h}$. Subsequently, sections were permeabilized and blocked in TBS with $0.1 \%$ Triton X-100 and 5\% normal donkey serum for $24 \mathrm{~h}$ at room temperature. Immunolabeling was carried out using primary antibodies directed against $\mathrm{Na}_{\mathrm{V}} 1.1$ (K74/ 71, mouse, IgG1, 1:100, NeuroMab) and parvalbumin (L114/3, 75-455, mouse, IgG2a, 1:100, NeuroMab). Subclass-specific secondary antibodies (488 and RRX) were used at 1:200 (Jackson ImmunoResearch Laboratories Inc.). All imaging was carried out on a Nikon A1 laser scanning confocal microscope. FIJI (National Institutes of Health) was used for image processing with settings consistently applied to across samples.

\section{Western blot}

Flash frozen samples ( $n=3$ per genotype) were prepared for Western blot using the Mem-PER Plus protein extraction kit (89842, Thermo Scientific) to isolate membrane and cytoplasmic protein fractions from mice aged P29-32. We ran $40 \mu \mathrm{g}$ of protein on $10 \%$ gels using the Mini-PROTEAN Tetra Cell Western blotting system (Bio-Rad). Anti-Na ${ }_{V} 1.1$ (Ab5204a, rabbit, 1:1000, Millipore) and anti-beta-actin (Ab8227, rabbit, 1:5000, Abcam) primary antibodies were incubated overnight in Odyssey blocking buffer (LI-COR). Secondary antibodies (IRDye 800CW Donkey anti-Rabbit IgG Secondary Antibody) were used at 1:5000 in Odyssey blocking buffer (LI-COR) for $1 \mathrm{~h}$ at room temperature. Blots were visualized using a LI-COR Odyssey CLx system and quantified in FIJI. Protein levels assayed via Western blot were compared by one-way ANOVA and Tukey's post hoc. 


\section{Mouse colony at UC Davis Medical Center}

Heterozygous $(+/-)$ breeders were transferred from the UC Davis Center of Neuroscience to the UC Davis Medical Center. Offspring were maintained on the C57BL/ $6 \mathrm{~N}$ background from The Jackson Laboratory (Bar Harbor, ME). Colonies were maintained with two breeding paradigms: wildtype $\left(1 \mathrm{~b}^{+/+}\right)$by heterozygous $\left(1 \mathrm{~b}^{+/-}\right)$and heterozygous $\left(1 \mathrm{~b}^{+/-}\right)$by heterozygous $\left(1 \mathrm{~b}^{+/-}\right)$crosses, giving rise to wildtype $\left(1 \mathrm{~b}^{+/+}\right)$, heterozygous $\left(1 \mathrm{~b}^{+/-}\right)$, and homozygous mice $\left(1 \mathrm{~b}^{-/-}\right)$. After weaning on PND 21, mice were socially housed in groups of $2-4$ by sex. Cages were housed in ventilated racks in a temperature $\left(68-72{ }^{\circ} \mathrm{F}\right)$ and humidity $(\sim 25 \%)$ controlled vivarium on a 12:12 light/dark cycle with lights on at 07:00, off at 19: $00 \mathrm{~h}$. Standard rodent chow and tap water were available ad libitum. In addition to standard bedding, a Nestlet square, shredded brown paper, and a cardboard tube were provided. All subjects were tested between 2 and 5 months of age. All measures were conducted by an experimenter blind to genotype.

\section{Behavioral assay design}

Both male and female subjects were used in this study. Subjects $\left(1 \mathrm{~b}^{+/+}-\right.$males $N=12$, females $N=14,1 \mathrm{~b}^{+/-}-$ males $N=15$, females $N=15$, and $1 \mathrm{~b}^{-/-}$- males $N=6$, females $N=6$ ) began the behavioral battery at 6 weeks of age. All behavioral tests were performed between 09: 00 and 17:00 h during the light phase of the 12:12 light/ dark cycle. Mice were brought to an empty holding room adjacent to the testing area at least $1 \mathrm{~h}$ prior to the start of behavioral testing. To minimize the carryover effects from repeated testing, assays were performed in the order of least to the most stressful tasks. Subjects were sampled from $1 \mathrm{~b}^{+/-} \times 1 \mathrm{~b}^{+/-}$and $1 \mathrm{~b}^{+/-} \times$ $1 \mathrm{~b}^{+/+}$pairings. The order and age of testing was as follows with at least 48-h separating tasks: (1) Elevatedplus maze at 6 weeks of age, (2) light dark conflict at 6 weeks of age, (3) open field at 7 weeks of age, (4) beam walking at 7 weeks of age, (5) rotarod at 8 weeks of age, (6) novel object recognition at 9 weeks of age, (7) spontaneous alternation at 10 weeks of age, (8) self-grooming at 11 weeks of age, (9) social approach at 11 weeks of age, (10) male-female social interaction at 12 weeks of age, (11) acoustic startle at 13 weeks of age, (12) prepulse inhibition at 13 weeks of age, and (13) fear conditioning at 14 weeks of age.

\section{Developmental milestones}

Developmental milestones were measured on postnatal day (PND) 2, 4, 6, 8, 10, and 12, as previously described $[50,51]$. Body weight, length (nose to edge of tail), and head width were measured using a scale (grams) and a digital caliper $(\mathrm{cm})$. Cliff avoidance was tested by placing each pup near the edge of a cardboard box, gently nudging it towards the edge, and measuring the time for it to turn and back away from the edge. Failures to avoid the cliff was recorded as a maximum score of $30 \mathrm{~s}$. Righting reflex was tested by placing each pup on its back, releasing it, and measuring the time for it to fully flip over onto four paws on each developmental day. Negative geotaxis was tested by placing each pup, facing downwards, on a screen angled at $45^{\circ}$ from parallel, and measuring the time for it to completely turn and to climb to the top of the screen. Failures to turn and climb were recorded as a maximum score of $30 \mathrm{~s}$. Circle transverse was tested by placing each pup in the center of a circle with a $5^{\prime \prime}(12.5 \mathrm{~cm})$ diameter drawn on a laminated sheet of $8.5^{\prime \prime} \times 11^{\prime \prime}$ white paper, and measuring the time for it to exit the circle. Failures to exit the circle were recorded as a maximum score of $30 \mathrm{~s}$.

\section{Elevated-plus maze}

The assay was performed using a mouse EPM (model ENV-560A) purchased from Med Associates (St. Albans, VT) and performed as previously described [52].

\section{Light $\leftrightarrow$ dark conflict}

The light $\leftrightarrow$ dark assay was performed in accordance with previously described procedures [52]. The mouse was allowed to explore freely for $10 \mathrm{~min}$. Time in the dark side chamber and total number of transitions between the light and dark side chambers were automatically recorded during the 10-min session.

\section{Open field}

General exploratory locomotion in a novel open field arena was evaluated as previously described [45, 50, 52]. Total distance traversed, horizontal activity, vertical activity, and time spent in the center were automatically measured to assess gross motor abilities in mice. Repeated measures ANOVA was used to detect differences in horizontal, vertical, total, and center time activity obtained during the open field assay. Multiple comparisons were corrected for using Sidak post hoc methods and F, degrees of freedom, and $p$ values are reported.

\section{Spontaneous alternation in a Y-maze}

Spontaneous alternation was assayed using methods modified based from previous studies [45] in mice. Oneway ANOVA was used to detect differences in alternation. Multiple comparisons were corrected for using Sidak post hoc methods and F, degrees of freedom, and $p$ values are reported.

\section{Novel object recognition}

The novel object recognition test was conducted as previously described [50, 53, 54]. The assay consisted of four sessions: a 30-min habituation session, a second 10- 
min habituation phase, a 10-min familiarization session, and a 5-min recognition test. Sniffing was defined as head facing the object with the nose point within $2 \mathrm{~cm}$ from the object. Time spent sniffing each object was scored by an investigator blind to both genotype and treatment. Recognition memory was evaluated by time spent sniffing the novel object versus the familiar object and innate side bias was accounted for by comparing sniff time of the two identical objects during familiarization. Within genotype repeated measures ANOVA was used to analyze novel object recognition using novel versus familiar objects as comparison. F, degrees of freedom, and $p$ values are reported.

\section{Balance beam walking}

Balance beam walking is a standard measure of motor coordination and balance $[55,56]$. We followed a procedure similar to methods previously described using our behavioral core [57]. Latency to traverse the length of the beam, number of footslips off the edge of the beam, and falls (if any) are scored by the investigator from coded video recordings. Approximately four trials per day for 3 days represents a standard training protocol.

\section{Rotarod}

Motor coordination, balance, and motor learning were assessed using an accelerating rotarod (Ugo Basile, Schwenksville, PA) as previously described $[58,59]$. The task requires the mice to walk forward in order to remain on top of the rotating cylinder rod. Mice were given 3 trials per day with a 30-60-min intertrial rest interval. Mice were tested over two consecutive days for a total of 6 trials. Latency to fall was recorded with a 300-s maximum latency.

\section{Repetitive self-grooming}

Spontaneous repetitive self-grooming behavior was scored as previously described [45, 52, 58, 60, 61]. Each mouse was placed individually into a standard mouse cage ( $46 \mathrm{~cm}$ long $\times 23.5 \mathrm{~cm}$ wide $\times 20 \mathrm{~cm}$ high). The first 10 -min was habituation and was unscored. Each subject was scored for cumulative time spent grooming all the body regions during the second $10 \mathrm{~min}$ of the test session.

\section{Three-chambered social approach}

Social approach was tested in an automated threechambered apparatus using methods similar to those previously described $[45,50,52,61,62]$. Three zones, defined using the EthoVision XT software, detected time in each chamber for each phase of the assay. Direction of the head, facing towards the cup enclosure, defined sniff time. The subject mouse was first contained in the center chamber for $10 \mathrm{~min}$, then allowed to explore all three empty chambers during a 10-min habituation session, then allowed to explore the three chambers containing a novel object in one side chamber and a novel mouse in the other side chamber. Lack of innate side preference was confirmed during the initial $10 \mathrm{~min}$ of habituation to the entire arena. Novel stimulus mice were $129 \mathrm{~Sv} / \mathrm{ImJ}$, a relatively inactive strain, aged 10-14 weeks, and matched to the $1 \mathrm{~b}$ mice by sex. Number of entries into the side chambers served as a within-task control for levels of general exploratory locomotion.

\section{Male-female social interaction}

The male-female reciprocal social interaction test was conducted as previously described $[45,52,58,60,61]$. Briefly, each freely moving male subject was paired for 5 min with a freely moving unfamiliar estrous WT female. Duration of nose-to-nose sniffing, nose-toanogenital sniffing, and following were scored using Noldus Observer 8.0XT event recording software (Noldus, Leesburg, VA). Ultrasonic vocalization spectrograms were displayed using Avisoft software, and calls were identified manually by a highly trained investigator blinded to genotype.

\section{Fear conditioning}

Delay contextual and cued fear conditioning was conducted using an automated fear-conditioning chamber (Med Associates, St Albans, VT, USA) as previously described $[45,50,52]$. Training consisted of a 2-min acclimation period followed by three tone-shock (CS-US) pairings $(80-\mathrm{dB}$ tone, duration $30 \mathrm{~s} ; 0.5-\mathrm{mA}$ footshock, duration $1 \mathrm{~s}$; intershock interval, $90 \mathrm{~s}$ ) and a 2.5 -min period during which no stimuli were presented. The environment was well lit $(\sim 100 \mathrm{~lx})$, with a stainless steel grid floor and swabbed with vanilla odor cue (prepared from vanilla extract; McCormick; 1:100 dilution). A 5min test of contextual fear conditioning was performed $24 \mathrm{~h}$ after training, in the absence of the tone and footshock but in the presence of $100 \mathrm{~lx}$ overhead lighting, vanilla odor, and chamber cues identical to those used on the training day. Cued fear conditioning, conducted $48 \mathrm{~h}$ after training, was assessed in a novel environment with distinct visual, tactile, and olfactory cues. The cued test consisted of a 3-min acclimation period followed by a 3-min presentation of the tone CS and a 90-s exploration period. Cumulative time spent freezing in each condition was quantified by VideoFreeze software (Med Associates).

\section{Acoustic startle and prepulse inhibition}

Subjects were tested in San Diego Instruments startle chambers using standard methods as described previously $[58,63]$. One trial type measured the response to 
no stimulus (baseline movement). The other five trial types measured startle responses to $40 \mathrm{~ms}$ sound bursts of $80,90,100,110$, or $120 \mathrm{~dB}$. The maximum startle amplitude over this sampling period was taken as the dependent variable. For prepulse inhibition of acoustic startle, mice were presented with each of seven trial types across six discrete blocks of trials for a total of 42 trials, over $10.5 \mathrm{~min}$. One trial type measured the response to no stimulus (baseline movement) and another measured the startle response to a $40 \mathrm{~ms}, 110 \mathrm{~dB}$ sound burst. The other five trial types were acoustic prepulse stimulus plus acoustic startle stimulus trials. The trial types were presented in pseudorandom order such that each trial type was presented once within a block. Prepulse stimuli were $20 \mathrm{~ms}$ tones of $74,78,82,86$, and 92 $\mathrm{dB}$ intensity, presented $100 \mathrm{~ms}$ before the $110 \mathrm{~dB}$ startle stimulus. The maximum startle amplitude over this sampling period was taken as the dependent variable. A background noise level of $70 \mathrm{~dB}$ was maintained over the duration of the test session.

\section{Seizure susceptibility following administration of pentylenetetrazole}

Subjects were weighed then administered pentylenetetrazole $(80 \mathrm{mg} / \mathrm{kg})$ intraperitoneally. Dosing was conducted in the morning (9:00-12:00) in a $\operatorname{dim}(\sim 30 \mathrm{~lx})$ empty holding room. Directly after administration of the convulsant, subjects were placed in a clean, empty cage, and subsequent seizure stages were live-scored for $30 \mathrm{~min}$. Seizure stages were scored using latencies to (1) first jerk/ Straub's tail, (2) loss of righting, (3) generalized clonictonic seizure, and (4) death. Time to each stage was taken in seconds and compared by genotype. Unpaired Student's $t$ tests were used to analyze latencies to first jerk, loss of righting, generalized clonic-tonic seizure, and death.

\section{Thermal induction of seizures in juveniles (febrile seizure paradigm)}

Subjects were acclimated to an arena for 10 min maintaining temperature at $37.5^{\circ} \mathrm{C}$. Temperature was increased $0.5^{\circ} \mathrm{C}$ every 2 min until animal showed behavioral seizure or a max temperature of $42.5^{\circ} \mathrm{C}$ was reached.

Observer recorded the type of seizure, and the temperature at which the behavioral seizure was observed using the Racine score from the literature for febrile seizures:

1. Staring

2. Head nodding

3. Unilateral forelimb clonus

4. Bilateral forelimb clonus

5. Rearing and falling

6. Clonic seizure

\section{EEG implantation}

Wireless EEG transmitters were implanted in anesthetized test animals using continuous isoflurane (2-4\%). A 2-3-cm midline incision was made over the skull and trapezius muscles, then expanded to expose the subcutaneous space. Implants were placed in the subcutaneous pocket lateral to the spine to avoid discomfort of the animal and displacement due to movement. Attached to the implant were 4 biopotential leads made of a NickelColbalt-based alloy insulated in medical-grade silicone, making up two channels that included a signal and reference lead. These leads were threaded towards the cranial part of the incisions for EEG and EMG placement. The periosteum was cleaned from the skull using a sterile cotton-tip applicator and scalpel then two 1-mm diameter burr holes were drilled $(1.0 \mathrm{~mm}$ anterior and 1.0 $\mathrm{mm}$ lateral; $-3.0 \mathrm{~mm}$ posterior and $1.0 \mathrm{~mm}$ lateral) relative to bregma. This lead placement allowed for measurement of EEG activity across the frontal cortical area. Steel surgical screws were placed in the burr holes and the biopotential leads were attached by removing the end of the silicone covering and tying the lead to its respective screw. Once in place, the skull screws and lead connections were secured using dental cement. For EMG lead placement, the trapezius muscles of the animal were exposed, and each lead was looped through and sutured to prevent displacement. Finally, the incision was sutured using non-resorbable suture material and the animals were placed in a heated recovery cage where they received Carprofen $(5 \mathrm{mg} / \mathrm{kg}$; i.p.) directly after surgery and $24 \mathrm{~h}$ post-surgery as an analgesic. Subjects were individually caged with ad libitum access to food and water for 1-week before EEG acquisition and monitored daily to ensure proper incision healing and recovery. Each implantation surgery took $<45 \mathrm{~min}$, and no fatalities were observed.

\section{EEG acquisition}

EEG data was acquired using Ponemah (Data Sciences International, St. Paul, MN, USA) and subsequently analyzed using the Neuroscore automated software (Data Sciences International, St. Paul, MN, USA). Subjects were recorded for 24-h baseline in their home cage before administration of $80 \mathrm{mg} / \mathrm{kg}$ pentylenetetrazole (Sigma Aldrich, St. Louis, MO, USA) injected intraperitoneally. EEG and EMG were continuously sampled at $500 \mathrm{~Hz}$. Spiking was defined as activity above an absolute threshold of $200-1000 \mu \mathrm{V}$ that lasted between 0.5 and $100 \mathrm{~ms}$, while spike trains had a minimum duration of $0.5 \mathrm{~s}$, a minimum spike interval of $0.05 \mathrm{~s}$, and a minimum of 4 consecutive spikes. Power spectral densities were determined using a periodogram transformation from amplitude to frequency domains then log transformed for clearer data illustration. Latency to seizure 
onset and subsequent death following administration of PTZ was first quantified by observed latencies then confirmed by spectral EEG and amplitude response readouts. One-way ANOVA was used to analyze bouts of spike train activity and latency to seizure onset and death between genotypes. An overall ANOVA was used to detect a genotype difference across power bands, then genotype differences were analyzed within power bands using multiple comparisons.

\section{Luciferase assay}

We constructed luciferase reporter plasmids by cloning a $\sim 900$-bp region containing human $1 \mathrm{~b}$ [30] into the pGL4.24 vector (Promega) upstream of the minP, primers in Table 4. HEK293 cells or SK-N-SH cells (40$60 \%$ confluent) were transfected using Lipofectamine 3000 (Invitrogen) with each construct ( $400 \mathrm{ng}$ ) and the Renilla luciferase expression vector pRL-TK (40 ng; Promega) in triplicate. After $24 \mathrm{~h}$, the luciferase activity in the cell lysates was determined using the Dual Luciferase Reporter System (Promega). Firefly luciferase activities were normalized to that of Renilla luciferase, and expression relative to the activity of an inactive region of noncoding DNA (NEG2) was noted.

\section{CRISPR/dCas9 in HEK293 cells}

HEK293 cells were transfected with $500 \mathrm{ng}$ of equimolar pooled SCN1A_h1b sgRNAs (Table 5) and $500 \mathrm{ng}$ dCas $9^{\mathrm{p} 300 \mathrm{Core}}$ (Addgene, plasmid \#61357) using Lipofectamine 3000 . After $24 \mathrm{~h}$, media was refreshed. Forty eight hours following transfection, RNA was collected using RNAqueous kit (Ambion) and cDNA was generated using Superscript III reverse transcriptase (Invitrogen). Changes in gene expression were quantified via qPCR using SYBR green, and primers are listed in Table 3.

\section{Results}

Scn $1 \mathrm{a} 1 \mathrm{a}$ and $1 \mathrm{~b}$ chromosomal regions physically interact and share chromatin signatures indicating pan-neuronal transcriptional activator regulatory activity

To define the regulatory landscape of the SCN1A locus, we examined publicly available chromosome conformation (Hi-C), transcriptomic and epigenomic data obtained from analysis of human and mouse brain tissues

Table 4 Primers for cloning regions from human DNA

\begin{tabular}{ll}
\hline Target & Sequence $\left(\mathbf{5}^{\prime}\right.$-3') \\
\hline human 1b & F-ttaattaagagctcCGGAAATCATTGCCCCTTCC \\
R-ttaattaactcgagAATCTGGATTGTGAGAAAGTGTT \\
Fuman NEG2 & F-ccggagctcTGGTATGGGTGAAAACGGCT \\
& R-cggctcgagGAGGTTGTGGGGAGGAGTG \\
\hline
\end{tabular}

(Fig. 1a, d, S1). We generated contact heatmaps from published Hi-C from prefrontal cortex [64] (PFC) at 10-kb resolution (Additional file 1: Fig. S1a), and for additional tissues at 40-kb resolution [64] (Additional file 1: Fig. S1c). In PFC, SCN1A was located at the boundary of two major TADs (topological associated domains), with extensive local interactions within the SCN1A locus. Differential analysis of Hi-C from PFC versus lung showed stronger local interactions in PFC (Additional file 1: Fig. S1b), while there were no major differences between the PFC and hippocampus, suggesting brain-specific local SCN1A chromosomal interactions (Additional file 1: Fig. S1c).

Previous work using 5' RACE [30] and luciferase assays defined regulatory sequences at $S C N 1 A$, including two genomic intervals, non-coding exons $1 \mathrm{a}$ and $1 \mathrm{~b}$, that are conserved between human and mouse and where the majority of SCN1A transcripts originate [30] (Fig. 1a). The locations of the 1a (GenBank: DQ993522) and 1b (GenBank: DQ993523) TSSs are shown as mapped in earlier work [30, 32]. DNA sequence at $1 \mathrm{a}$ and $1 \mathrm{~b}$ is highly evolutionarily conserved across vertebrates. Notably, conservation at $1 \mathrm{~b}$ extends nearly $3 \mathrm{~kb}$ downstream of the defined UTR transcribed sequence. Interaction models from an independent capture $\mathrm{Hi}-\mathrm{C}$ dataset [64] also suggested physical interaction between $1 \mathrm{a}$ and $1 \mathrm{~b}$ as well as between $1 \mathrm{~b}$ and the nearby $T T C 21 B$ promoter (Fig. 1a).

We examined chromatin state at the SCN1A locus across seven histone post-translational modifications (PTMs) from human mid frontal lobe [40] (Fig. 1a). The strongest chromatin signatures for regulatory elements were at the previously defined $1 \mathrm{a}$ and $1 \mathrm{~b}$ loci, with H3K27ac, H3K4me3 and H3K9ac, weak H3K4me1, and absence of H3K27me3, H3k9me3, and H3K36me3 in these regions. In ATAC-seq and H3K27ac across the majority of non-CNS tissues profiled in the ENCODE or Roadmap projects [40], $1 \mathrm{a}$ and $1 \mathrm{~b}$ show reduced or absent signal, further indicating primary importance in the nervous system. In addition to $1 \mathrm{a}$ and $1 \mathrm{~b}$, there were several other non-coding regions showing weaker, but still significant enrichment for H3K27ac in brain, representing potential additional $S C N 1 \mathrm{~A}$ regulatory elements. ATAC-seq from neuronal and non-neuronal cells from dorsolateral PFC (DLPFC) [42] showed that neuronal cells have increased chromatin accessibility across SCN1A generally (Fig. 1a), with specific enrichment at $1 \mathrm{a}, 1 \mathrm{~b}$, and a third region also within the first intron of SCN1A. Comparing human neuronal data with mouse ATAC-seq and histone PTM data [43], accessibility and chromatin states appeared largely conserved (Fig. 1a, d). Finally, ATAC-seq data [43] from sorted neuronal subtypes in mouse, including excitatory neurons and parvalbumin (PV) and vasoactive intestinal peptide (VIP) 
Table 5 sgRNA sequences for CRISPR dCas9 induction

\begin{tabular}{lll}
\hline Target & Sequence (5'-3') & Location (hg19) \\
\hline h1b_1 & GCTATTGCTGATTGTATTAGG & Chr2: 166128022 166128044 \\
h1b_2 & GAGGATACTGCAGAGGTCTCTGG & Chr 2: 166984479-166984501 \\
h1b_3 & GGAAGGTTGAGAGAGGAGGGGGG & Chr 2: 166984086-166984108 \\
h1b_4 & AGTATCTGCAGTATCATTGCTGG & Chr 2: 166983556166983578 \\
h1b_5 & GGAAAATTCCATGCTGAGGTTGG & Chr 2: 166983037166983059 \\
h1b_6 & TGAATGGCCACAGAGATTACGG & Chr 2: 166982669166982691 \\
\hline
\end{tabular}

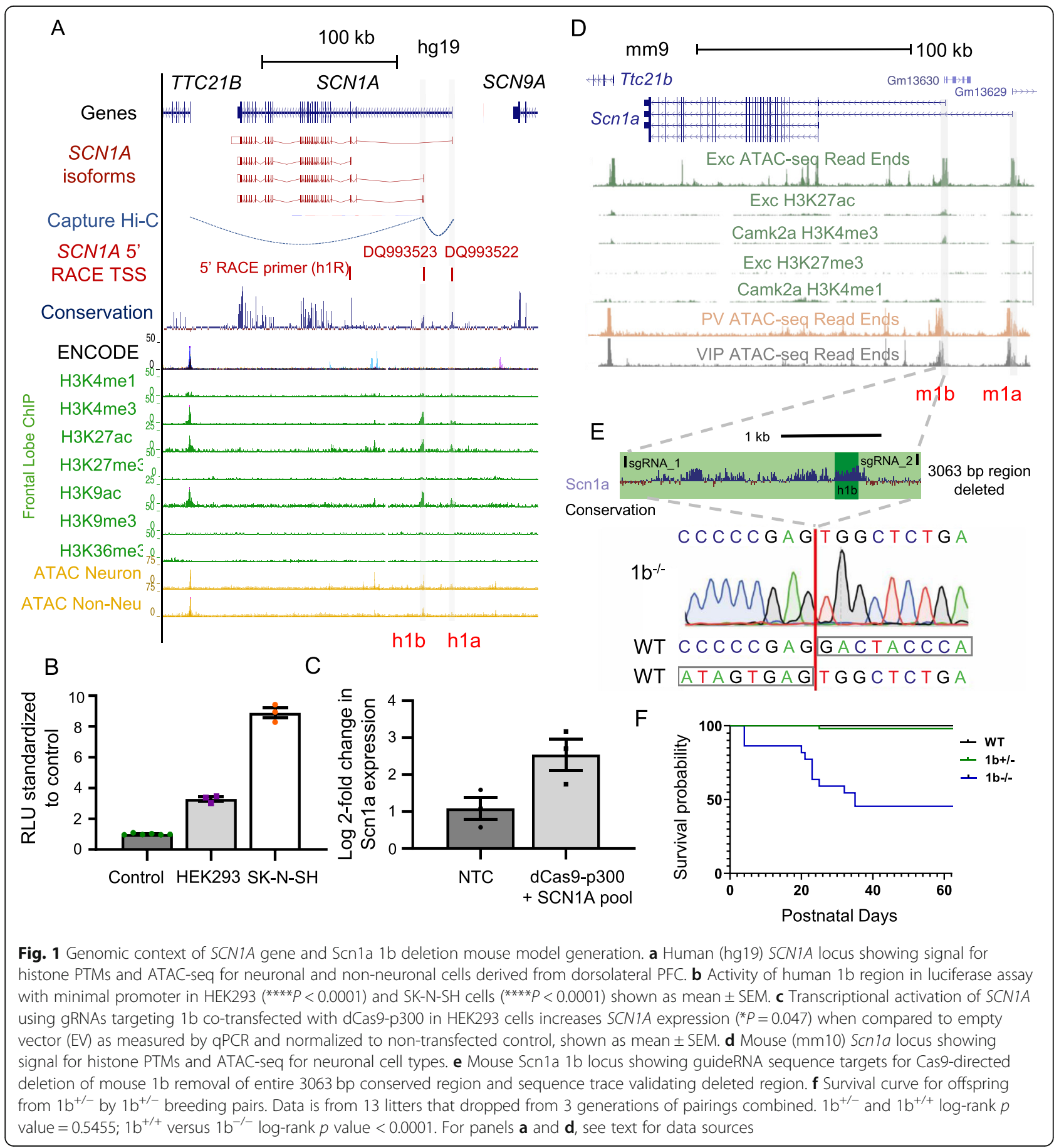


interneurons, indicated consistent open chromatin at Scn1a 1a and 1b across neuron types (Fig. 1d).

\section{The evolutionarily conserved Scn $1 \mathrm{a} 1 \mathrm{~b}$ non-coding region acts as a Scn1a transcriptional activator and is essential for survival}

Taken together, the comparative and functional genomics data indicates evolutionarily conserved brain-specific pan-neuronal regulatory and TSS activity of $1 \mathrm{a}$ and $1 \mathrm{~b}$, with evidence for chromosomal physical interaction between the two promoters. The $1 \mathrm{~b}$ region has been annotated as an alternative TSS, yet the extended region surrounding the annotated transcribed UTR also shows the strongest enrichment for evolutionary conservation and for chromatin signatures associated with strong enhancer activity (i.e., H3K27ac and H3K4me3) across non-coding regions of the $S C N 1 A$ locus. We sought to validate the specific role of $1 \mathrm{~b}$ DNA in activation of SCN1A expression. We used luciferase assay to functionally test the core human $1 \mathrm{~b}$ (h1b) region in cell lines. A 941-bp region containing $1 \mathrm{~b}$ and conserved flanking sequence induced expression in HEK293 and SK-N-SH cells when cloned into a vector with a minimal promoter (Fig. 1b). To further demonstrate the regulatory role of $1 \mathrm{~b}$ in SCN1A expression, we showed that a pool of 6 sgRNAs targeted to human $1 \mathrm{~b}$ sequence and delivered along with dCas9-p300, an inactivated Cas9-histone acetyltransferase fusion protein [65], was sufficient to induce SCN1A expression 2.5-fold in HEK293 cells compared to non-transfected control (Fig. 1c).

The strength of evolutionary conservation and transcriptional activation-associated epigenomic signatures at the extended $1 \mathrm{~b}$ interval is paradoxical considering its presumed role as a secondary TSS. Thus, we sought to test whether the extended $1 \mathrm{~b}$ regulatory region is essential for Scn1a expression, and whether loss of this element is sufficient to produce seizures and DS-relevant phenotypes in mice. We used CRISPR/Cas9 targeting of C57BL/6N oocytes to generate mice harboring a 3063bp deletion of the interval flanking the $1 \mathrm{~b}$ regulatory element of $S c n 1 a$, removing the entire mammalian conserved region (Fig. 1e). We expanded this Scn1a $1 b$ deletion line (hereafter referred to as $1 \mathrm{~b}$ ) via at least six generations of breeding to wildtype C57BL/6N (WT) mice, eliminating potential off-target Cas9-induced mutations.

Previous studies have found that mice harboring homozygous coding mutations to Scn1a die in the third postnatal week and mice with heterozygous coding mutation exhibit reduced survival $[20,26]$. In comparison, 46 female WT by heterozygous male $\left(1 \mathrm{~b}^{+/-}\right)$harem trio pairings yielded 41 litters, and survival rates of $1 \mathrm{~b}^{+/-}$and WT littermate pups were indistinguishable $(\log -\operatorname{rank} p=$ 0.8458 ); however, female $1 \mathrm{~b}^{+/-}$by $1 \mathrm{~b}^{+/-}$male harem trios required nearly double the number of pairings $(n=$ 74) to produce only 13 litters. This was caused by both reduced rates of pregnancy, as determined via regularly weighing females, and by increased litter cannibalism in the neonatal period. Among the 13 litters that were produced, the three genotypes were born at expected Mendelian frequencies (Additional file 2: Table S1). While survival rates for $1 \mathrm{~b}^{+/-}$and WT littermate pups from these litters were indistinguishable (log-rank $p=0.5455)$, $48 \%$ of homozygous $1 \mathrm{~b}$ deletion $\left(1 \mathrm{~b}^{-/-}\right)$mice died by weaning (Fig. 1f, log-rank $p<0.0001$ ). Thus, $1 \mathrm{~b}^{+/-}$mice survive, but female carriers were less efficient at producing viable litters, severely impacting generation of homozygous $1 \mathrm{~b}$ deletion offspring. $1 \mathrm{~b}^{-l-}$ pups were visibly smaller and failed to thrive, though around half survived to maturity. In addition, $1 \mathrm{~b}^{-/-}$exhibited spontaneous seizures during routine handling, consistent with expected neurological impact of significant decrease in Scnla expression.

We tested $1 \mathrm{~b}^{+/-}$mice for measures of general health and utilized a Fox developmental battery [51] and found no deficits in growth, reflexes, and limb strength (Additional file 3: Table S2). $1 \mathrm{~b}^{-/-}$pups were not evaluated for these milestones, as spontaneous seizures were observed, so handling was minimized to increase survival.

\section{Loss of extended $1 \mathrm{~b}$ interval causes loss of $\mathrm{Na}_{\mathrm{v}} 1.1$ across postnatal brain regions}

We first sought to test if $1 \mathrm{~b}$ ablation resulted in changes in amount and regional distribution of Scn1a transcript and $\mathrm{Na}_{V} 1.1$ protein in mouse brain. Expression of $S c n 1 a / \mathrm{Na}_{\mathrm{V}} 1.1$ begins in the early postnatal period and reaches high expression throughout the brain by 4 weeks of age [66]. We focused on the cerebellum, hippocampus, and cortex, where we detected $\mathrm{Na}_{\mathrm{V}} 1.1$ by immunohistochemistry in WT mice by P28 (Fig. 2a-c). We tested for reduced Scn1a RNA expression via quantitative reverse-transcription PCR (qRT-PCR) performed on cortex, hippocampus, and cerebellum of 3-month-old Scn1a 1b deletion carriers and WT littermates (WT $n=4,1 \mathrm{~b}^{+/-} n=5$, $1 \mathrm{~b}^{-/-} n=7$ ) (Fig. 2d). In agreement with GTEx [32] and previous studies [30], we observed the highest level of WT Scn1a expression in the cortex with expression in cerebellum and hippocampus 34\% and $60 \%$ lower, respectively. When comparing $1 \mathrm{~b}$ deletion to WT mice (ANOVA with Tukey's post hoc), there was a reduction in Scn1a expression as measured by qPCR in $1 \mathrm{~b}^{-/-}$mice in all 3 regions tested (reduced by $57 \%$ in the cortex, $62 \%$ in the hippocampus and $59 \%$ in the cerebellum). $1 \mathrm{~b}^{+/-}$Scn $1 \mathrm{a}$ expression was not significantly reduced versus WT, but did show a trend towards an intermediate level between WT and $1 \mathrm{~b}^{-/-}$levels (Fig. 2d). 


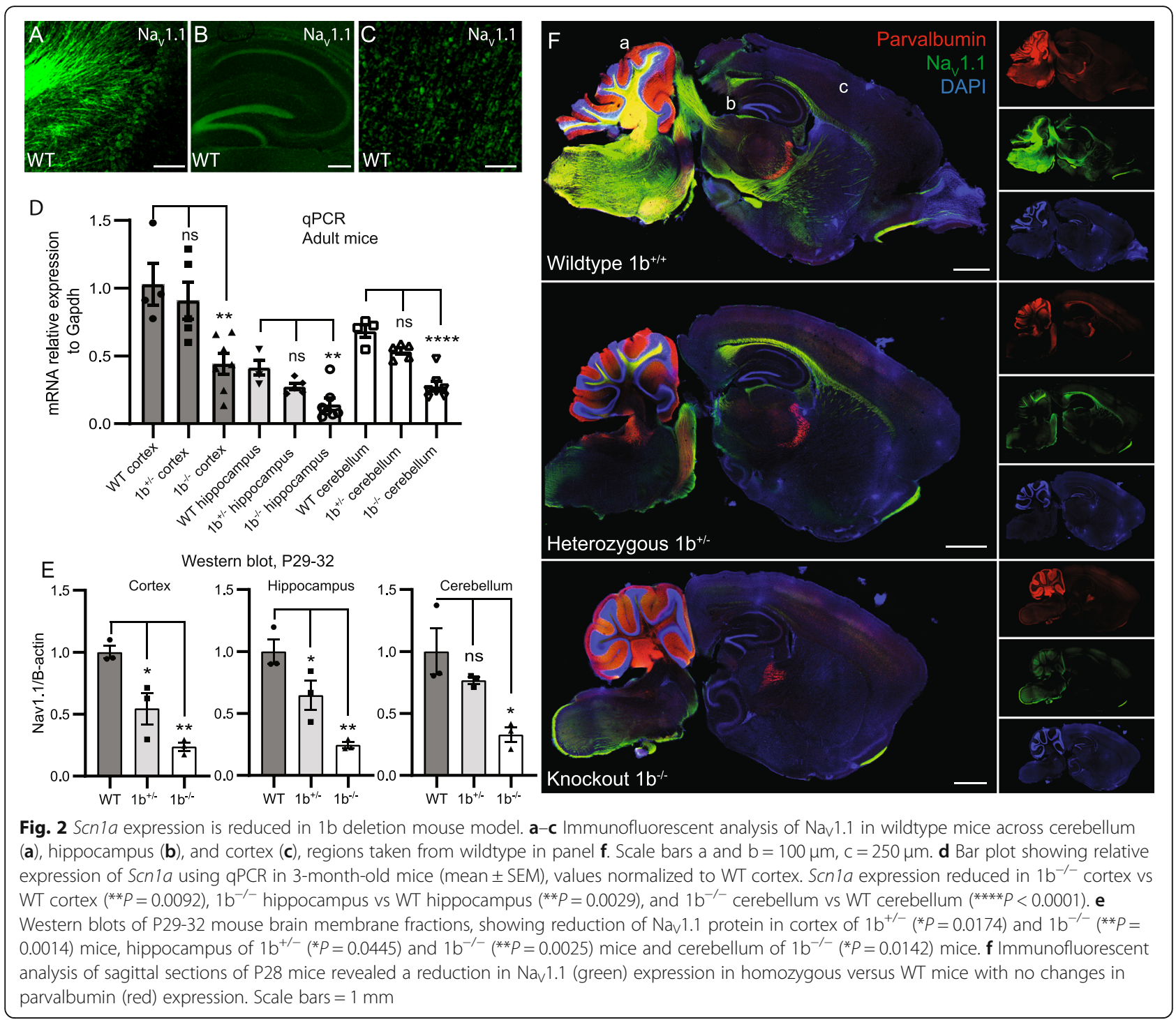

Reduction in protein expression across the mouse brain was evaluated by Western blot analysis of the membrane fraction from prepared cortex, hippocampus, and cerebellum from mice aged P29-32 $(n=3$ each genotype). $1 \mathrm{~b}^{-/-}$mice had significantly decreased $\mathrm{Na}_{\mathrm{V}} 1.1$ protein expression (ANOVA with Tukey's post hoc) compared to WT in all three regions, and $1 \mathrm{~b}^{+/-}$showed significant decreased expression in cortex and hippocampus and a trend towards reduced levels in cerebellum (Fig. 2e). $\mathrm{Na}_{\mathrm{V}} 1.1$ expression was reduced by $45 \%$ in $1 \mathrm{~b}^{+/-}$mice and $76 \%$ in $1 \mathrm{~b}^{-/-}$mice in the cortex, $35 \%$ in $1 \mathrm{~b}^{+/-}$mice and $75 \%$ in $1 \mathrm{~b}^{-/-}$mice in the hippocampus, and by $23 \%$ in $1 \mathrm{~b}^{+/-}$mice and $67 \%$ in $1 \mathrm{~b}^{-/-}$in the cerebellum (Fig. 2e). Raw Western blots including blots of the cytoplasmic fraction can be seen in Additional file 1: Fig. S2. These results are consistent with qPCR results and show that deletion of the extended $1 \mathrm{~b}$ interval had a larger than expected impact on Scn1a and $\mathrm{Na}_{\mathrm{V}} 1.1$ expression considering the proportion of transcripts expected to originate at this element.

With immunofluorescence (IF), we compared qualitative distribution of expression of $\mathrm{Na}_{\mathrm{V}} 1.1$ along with the interneuron marker parvalbumin across $1 \mathrm{~b}^{-/-}$, $1 \mathrm{~b}^{+/-}$, and $1 \mathrm{~b}^{+/+}$mice at P28 $(n=3$ each genotype) (Fig. 2f and raw images in Additional file 1: Fig. S3). Notably, deletion of $1 \mathrm{~b}$ appeared to generally reduce $\mathrm{Na}_{V} 1.1$ expression, rather than specifically impact certain brain regions, consistent with $5^{\prime}$ RACE TSS activity [30]. Consistent with Western blot quantifications, there was subtle apparent reduction in $\mathrm{Na}_{\mathrm{V}} 1.1$ IF in the brainstem and midbrain between WT and $1 \mathrm{~b}^{+/-}$mice, while $1 \mathrm{~b}^{-/-}$mice had obvious reduction of expression in the brainstem, midbrain, cerebellum, and hippocampus. 
Adult mice harboring heterozygous $1 \mathrm{~b}$ deletion are susceptible to seizures and exhibit abnormal EEG activity Given the general failure to thrive, developmental lethality, and spontaneous behavioral seizures in homozygous $1 \mathrm{~b}^{-/-}$mice, we focused on heterozygous $1 \mathrm{~b}^{+/-}$mice to test for more subtle phenotypes associated with two seizure induction paradigms, exposure to heat and the chemoconvulsant pentylenetetrazole (PTZ), paired with EEG recording. Thermal-evoked seizures are a hallmark of DS and SCN1A-associated epilepsy models [67, 68], and thus, we tested whether these were induced in $1 \mathrm{~b}^{+/-}$ mice. P22 $1 \mathrm{~b}^{+/-}$mice and WT littermates $(n=9$ per genotype of mixed sex) were subjected to a gradual $0.5^{\circ} \mathrm{C}$ increase in body temperature every $2 \mathrm{~min}$ from $37.5^{\circ} \mathrm{C}$ to $42.5^{\circ} \mathrm{C}$, mimicking the increase in body temperature during a fever. $1 \mathrm{~b}^{+/-}$mice displayed heatinduced behavioral seizures at $41.5^{\circ} \mathrm{C}$ (Fig. 3a) as measured by the Racine scale (Fig. 3b) while WT did not present with seizures (Fig. 3a, b).

To corroborate and further characterize induced seizure susceptibility, we used a second paradigm, PTZ seizure induction [69]. First, we performed a dose response analysis on mice of the C57BL/6 $\mathrm{N}$ background strain to identify a PTZ dose that allowed for observations of all stages of behavioral seizure in addition to EEG seizures (Additional file 1: Fig. S4). To test for induced seizure susceptibility, male and female $1 \mathrm{~b}^{+/-}$and WT littermate mice were intraperitoneally administered $80 \mathrm{mg} / \mathrm{kg}$ of PTZ. After administration, latencies to first jerk, loss of righting, generalized clonic-tonic seizure, and full tonic extension were measured. In comparison to WT littermates, PTZ-treated $1 \mathrm{~b}^{+/-}$mice exhibited increased seizure susceptibility across all measures (Fig. 4a-d: first jerk $t_{(1,30)}=2.171, p=0.038$; loss of righting $t_{(1,30)}=$ 2.160, $p=0.039$; generalized clonic-tonic seizure $t_{(1,30)}$ $=2.128, p=0.042$; full tonic extension $t_{(1,30)}=2.207$, $p=0.035$, unpaired Student's $t$ tests).
Finally, to test for spontaneous neurophysiological phenotypes in $1 \mathrm{~b}^{+/-}$mice and to link PTZ-induced behavioral seizures with electrophysiological activity, skull screws for EEG and EMG were implanted in a second group of animals of both sexes and recordings were made over a 24-h interval, with PTZ induction at the end of the recording period. Comparison of EEG signatures for $1 \mathrm{~b}^{+/-}$and WT littermates prior to PTZ administration show elevated spontaneous spiking events and spike trains in $1 \mathrm{~b}^{+/-}$mice and increased power spectral density signatures (Fig. 4e, f). Spiking activity measured by bouts of spike trains was significantly higher in $1 \mathrm{~b}^{+/-}$ when compared to WT littermate controls (Fig. 4g: $t$ (1, $8)=3.812, p=0.005)$, indicating heightened excitability. $1 \mathrm{~b}^{+/-}$deletion subjects also had higher power detected across all frequency bins when compared to WT (Fig. 4h: $\mathrm{F}(1,8)=423.9, p<0.0001$, multiple comparisons all had $p<0.0001)$. At the end of the recording period, PTZ administration in implanted mice reproduced the faster latency to seizure onset and trends towards faster latency to death (Fig. 4i, j: $t(1,8)=3.920, p=0.004, t(1,8)=$ 2.103, $p=0.068$, compared to WT by unpaired $t$ tests), and revealed corresponding increases in EEG activity in response to PTZ. There were no sex differences in induced seizure or EEG outcomes in $1 \mathrm{~b}^{+/-}$mice. Overall, these experiments revealed elevated spontaneous EEG spiking and irregular neural signatures, and link PTZinduced behavioral seizures with increased neurophysiological activity in $1 \mathrm{~b}^{+/-}$mice.

\section{Homozygous but not heterozygous $1 \mathrm{~b}$ deletion causes cognitive deficits in novel objection recognition (NOR) and spontaneous alternation in the $\mathrm{Y}$-maze}

To investigate the impact of $1 \mathrm{~b}$ deletion on behavior, we performed a tailored battery focused on learning and memory and motor abilities on $1 \mathrm{~b}^{+/-}$and surviving $1 \mathrm{~b}^{-/-}$male and female mice (see "Methods" section for
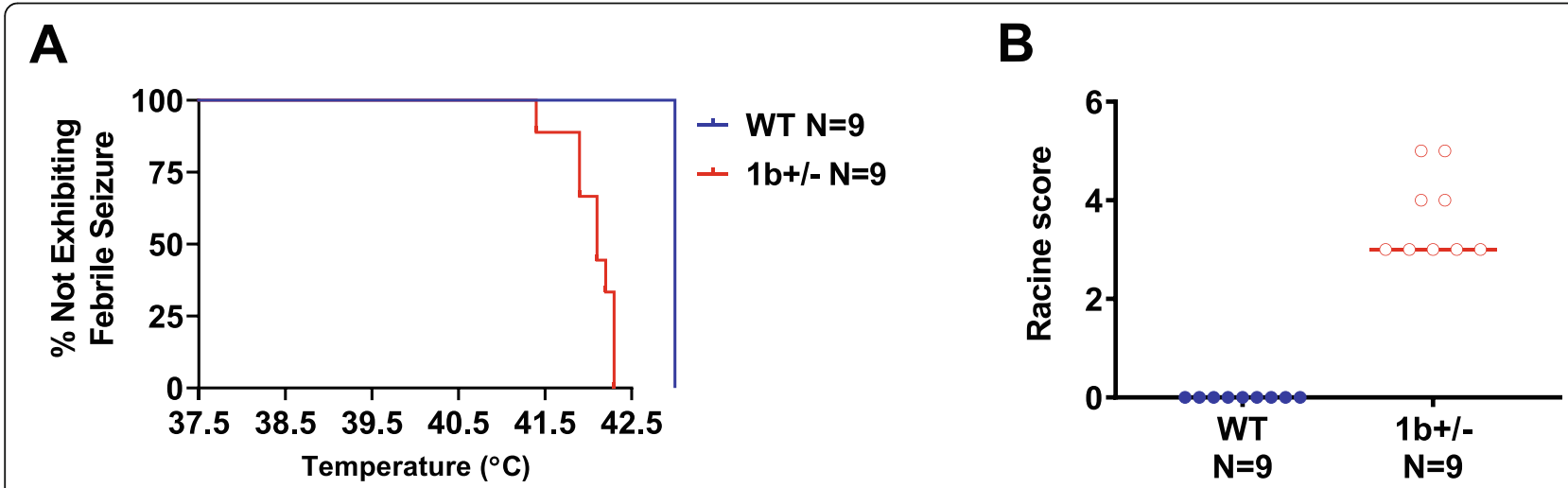

Fig. 3 Thermal-evoked febrile seizures in $1 b^{+/-}$mice and $W T$ littermates. a The $1 b^{+/-}$mice began to have seizures at $41.5^{\circ} \mathrm{C}(\mathbf{b})$ as measured by the Racine scale 


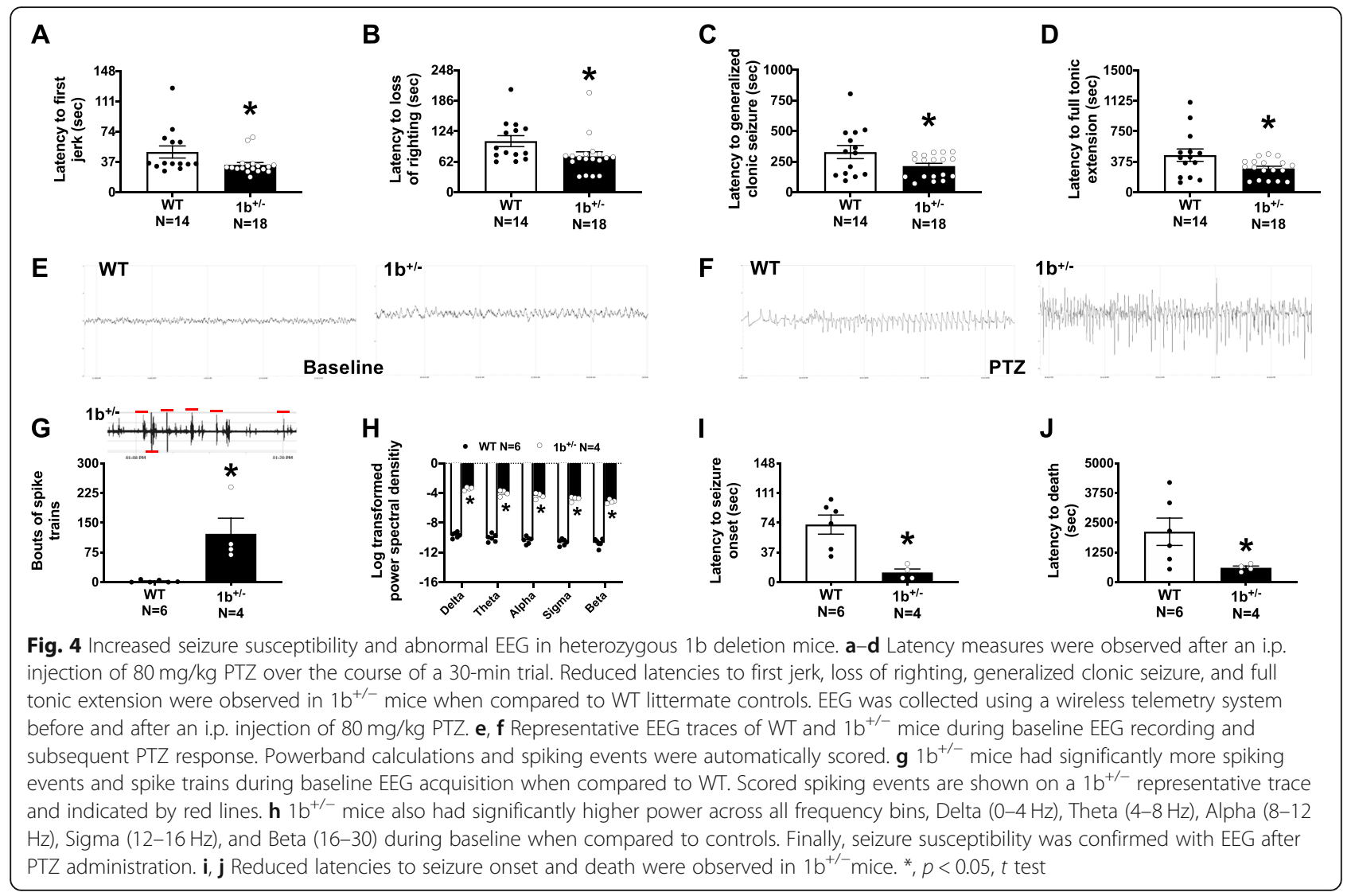

details). $1 \mathrm{~b}^{+/-}$mice of both sexes were additionally tested in a comprehensive behavioral battery of standard assays of overall physical health across development, sensorimotor reflexes, motor coordination, anxiety-like, and social behavior to test for subtler phenotypes that might be present in the heterozygous mutants. Details of the administration of behavioral testing are described in "Methods", and results from these experiments are summarized in Additional file 4: Table S3.

Cognitive deficits were observed in $1 \mathrm{~b}^{-/-}$but not $1 \mathrm{~b}^{+/-}$ mice in two corroborating assays of learning and memory, NOR, and Y-maze. Following established NOR methods $[50,53]$, manual scoring by a highly trained observer blinded to genotype indicated WT and $1 \mathrm{~b}^{+/-}$mice spent more time investigating the novel object versus the familiar object, as expected. In contrast, $1 \mathrm{~b}^{-/-}$homozygous mice did not exhibit typical novel object preference (Fig. 5a: within genotype repeated measures (paired $t$-test) WT $p=0.002 ; 1 \mathrm{~b}^{+/-}$mice $p=0.018$, *, novel versus familiar), illustrating recall of the familiar object and learning. Yet the $1 \mathrm{~b}^{-/-}$mice did not exhibit this typical learning and memory $(p=0.8698)$. Sexes were combined since there was no sex difference observed on time spent sniffing objects (Additional file 5: Table S4). Control data illustrating no preference for the left or right objects and sufficient time spent investigating the objects is shown in Fig. 5b. $1 b^{-/-}$mice were also impaired on the Y-maze, making less alternation triads compared to WT and $1 \mathrm{~b}^{+/-}$mice (Fig. 5c: $\mathrm{F}_{(2,62)}=5.693, p<0.005$ ). Sidak's multiple comparisons indicated the $1 \mathrm{~b}^{-1-}$ differed from the WT $(p=0.0192)$ and $1 \mathrm{~b}^{+/-}(p=0.0047)$ mice.

Most parameters of gross motor skills and motor coordination were similar across genotypes (Additional file 4: Table S3). In the open field novel arena assay of locomotion, $1 \mathrm{~b}^{-1-}$ were hyperactive during $10 \mathrm{~min}$ of the 30 min session. The time course for horizontal, total, and vertical activity was as expected across time, showing normal acclimation to the arena in all genotypes. Horizontal and vertical activity did not differ between genotypes (Fig. 5d, e; $\mathrm{F}_{(2,80)}=0.1401, p>0.05$ ). However, $1 \mathrm{~b}^{-/-}$mice were hyperactive in total activity (Fig. 5f; $\mathrm{F}_{(2 \text {, }}$ 80) $=5.117, p<0.008$, Two-way repeated measures ANOVA, genotype $\times$ time). Sidak's multiple comparisons indicated comparisons between the $1 b^{-/-}$versus the WT mice differed at time of bins 11-15 $(p=0.0014)$ and differed between the $1 \mathrm{~b}^{-/-}$and $1 \mathrm{~b}^{+/-}$mice at time bins of $11-15(p<0.0001)$ and $16-20(p=0.0270)$. In addition to highlighting a clear hyperactive phenotype in the $1 \mathrm{~b}^{-/-}$mice, linked to DS and numerous NDDs [70, $71]$, these results indicate that there were no gross motor 


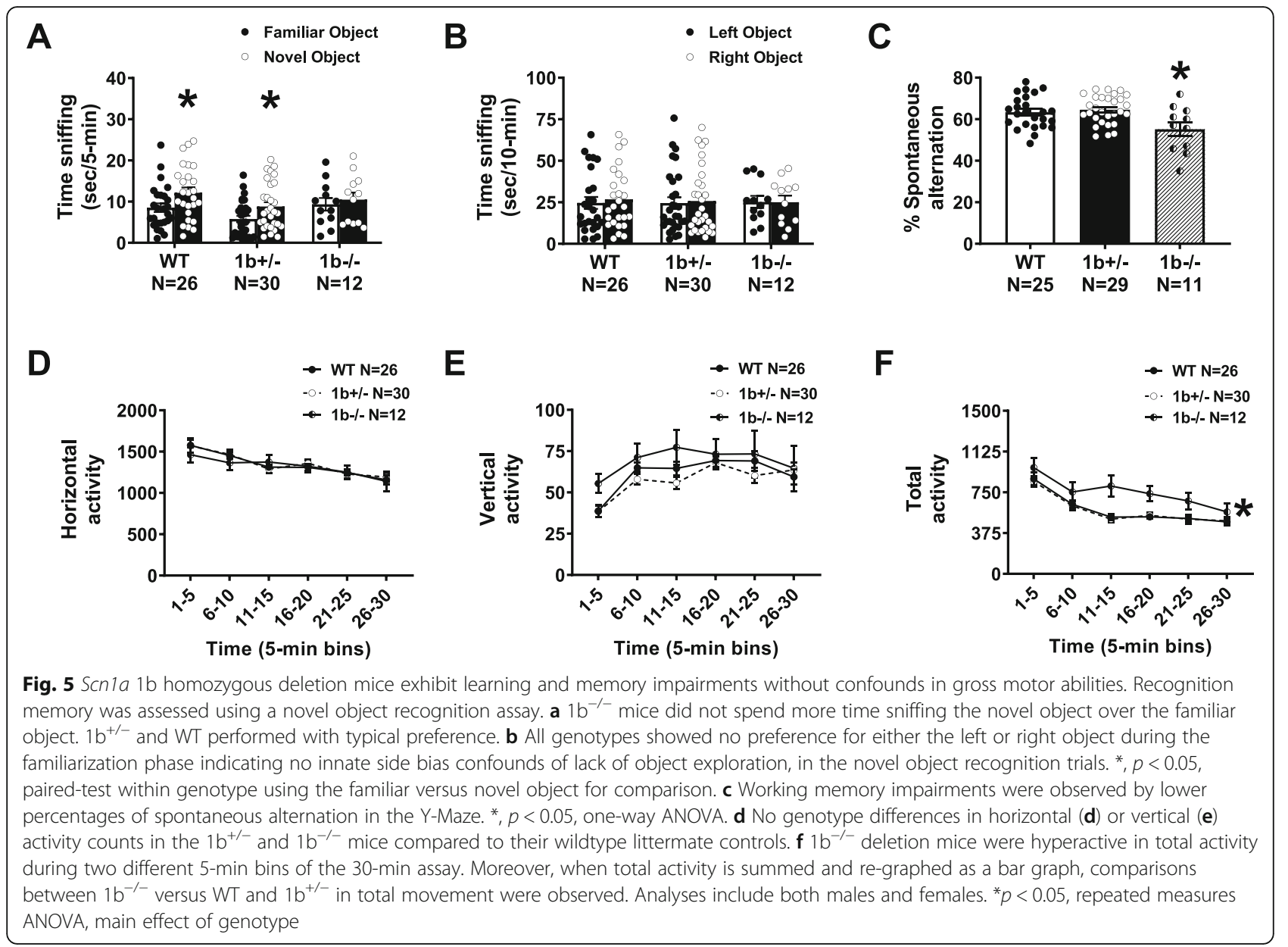

abnormalities, inability to rear, or hindlimb weakness that would prevent movement in the learning and memory assays that utilized objects and maze exploration.

$1 \mathrm{~b}^{+/-}$mice did not exhibit significant consistent phenotypes in a comprehensive battery of assays standard for examining mouse models of NDDs (Additional file 4: Table S3). For example, $1 \mathrm{~b}^{+/-}$mice spent less time in the dark chamber in the light-dark assay $\left(t_{(1,69)}=2.121, p=0.0375\right.$, unpaired two-tailed $t$-test) suggesting elevated anxiety-like behavior, yet no corroborative significance was observed in the plus maze. Reduced male-female ultrasonic vocalizations in $1 \mathrm{~b}^{+/-}$males in the reciprocal social interaction test alludes to aberrant social communication but no corroborative social behavior events were detected $\left(t{ }_{(1}\right.$, $25)=2.143, p=0.0420$, unpaired two-tailed $t$-test). Also, a three-chambered approach was typical. Applying rigorous standards used for behavioral studies of NDD models, the absence of two corroborating assays or indices of anxiety-like behavior and sociability precludes us from interpreting these findings as robust phenotypes [72, 73]. For all behavioral assays, no sex differences were identified between male and female $1 \mathrm{~b}$ deletion mice (Additional file 5: Table S4).

\section{Differential gene expression in Scn1a 1b deletion mouse hippocampus}

We used RNA sequencing (RNA-seq) at P7 and P32 to examine Scn1a isoform expression and transcriptional pathology associated with $1 \mathrm{~b}$ deletion. At P7, forebrain from WT $(n=2), 1 \mathrm{~b}^{+/-}(n=4)$, and $1 \mathrm{~b}^{-/-}(n=2)$ mice was compared. At P32, analysis was performed on microdissected hippocampus tissue in two rounds. We focused on hippocampus as an example P32 tissue, as hippocampal ablation of Scn1a has been specifically linked to seizure and DS-relevant cognitive deficits in mice [74]. For P32, we first compared $1 \mathrm{~b}^{-/-}(n=2)$ and WT $(n=2)$ mice using $50 \mathrm{bp}$ single-end read approach. Next, we compared of WT $(n=3)$ and $1 \mathrm{~b}^{+/-}(n=4)$ mice using $150 \mathrm{bp}$ paired-end read methods in order to more deeply sample reads covering the $1 \mathrm{a}$ and $1 \mathrm{~b}$ UTR region of the Scnla transcript.

At both P7 and P32, Scn1a expression showed significant $1 \mathrm{~b}$ dosage-dependent decrease using an additive 


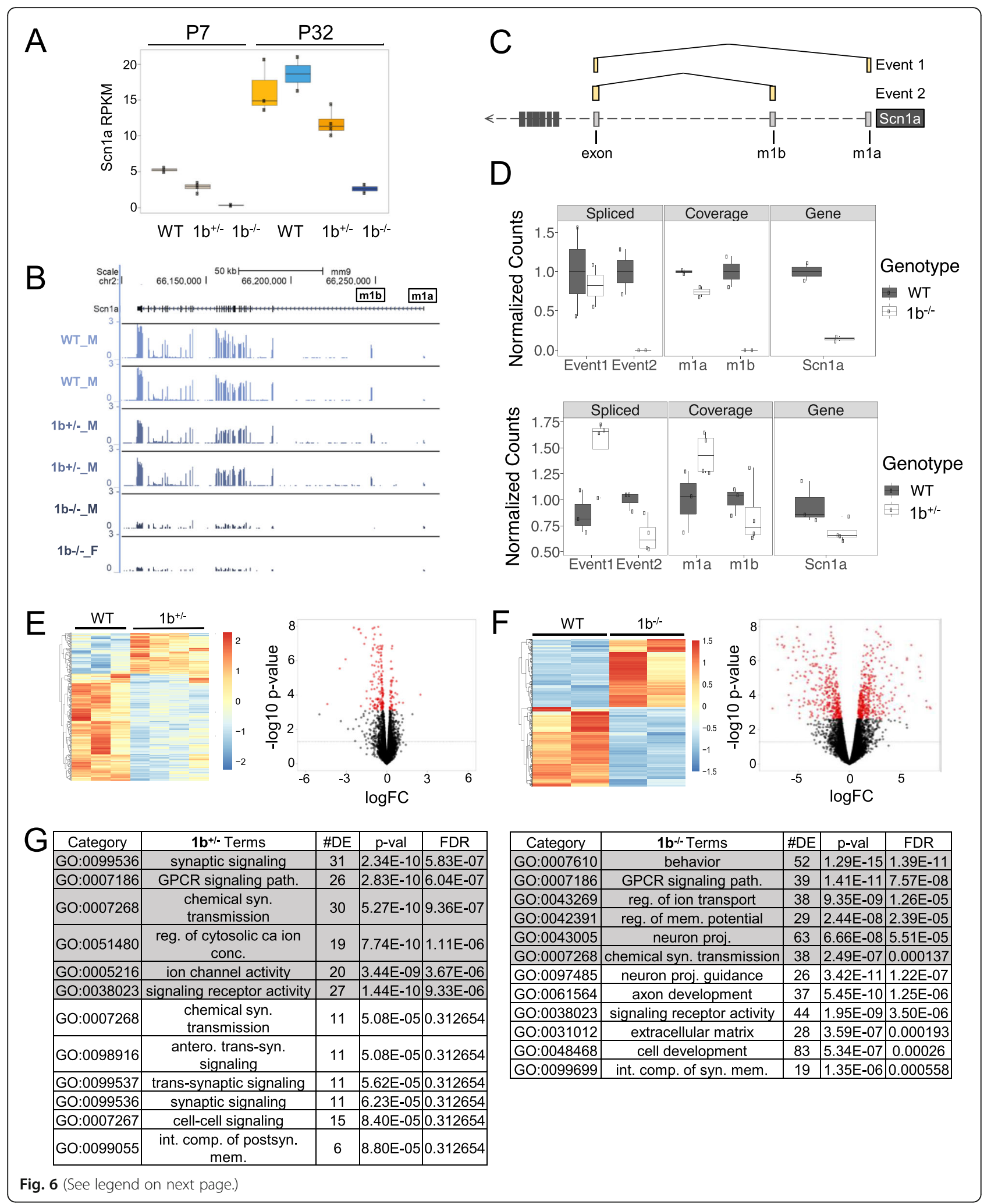


(See figure on previous page.)

Fig. 6 Differential gene expression with Scnla $1 \mathrm{~b}$ deletion. a Bar plot indicating RPKM Scn1a expression between WT and 1 $\mathrm{b}^{+/-}$or $1 \mathrm{~b}^{-/-}$mutants in postnatal day (P) 7 forebrain or P32 hippocampus, (mean \pm SEM). b Mouse (mm9) Scnla locus showing decrease in coverage in representative P32 heterozygous and homozygous $1 \mathrm{~b}$ deletion carriers compared to wildtype controls. c Schematic showing splicing of $\mathrm{m} 1 \mathrm{a}$ and $\mathrm{m} 1 \mathrm{~b}$ sequences with first Scnla coding exon in reference. d Bar plots showing the number of sequencing reads that overlap each splicing event, $\mathrm{m} 1 \mathrm{~b}$ or m1a locus, and the entire Scn 1a locus along the $x$-axis for P32 WT, $1 \mathrm{~b}^{+/-}$, and $1 \mathrm{~b}^{-/-}$mice. The full table is included in the supplement. $\mathbf{e}$ Heatmap and scatterplot of differentially expressed genes in P32 1b $\mathrm{b}^{+/-}$mice. In the scatterplot, genes with FDR $<0.05$ are in red while the dashed line indicates a $p$ value $<0.05$. f Heatmap and scatterplot of differentially expressed genes in P32 $1 \mathrm{~b}^{-1-}$ mice. In the scatterplot, genes with FDR $<$ 0.05 are in red while the dashed line indicates a $p$ value $<0.05$. $\mathbf{g}$ Table showing select pathways enriched in differentially expressed genes for P32 $1 \mathrm{~b}^{+/-}$(left) or $1 \mathrm{~b}^{-/-}$(right) mice. Pathways enriched in downregulated genes are shown in gray. Pathways enriched in upregulated genes are shown in white. Ontologies are biological pathways (BP), molecular function (MF), or cellular component (CC)

model (Additional file 6: Table S5-7). Scn1a expression was reduced compared to WT in $1 \mathrm{~b}^{+/-}$and $1 \mathrm{~b}^{-/-}$mice at P7, though this decrease was only independently significant in $1 \mathrm{~b}^{-/-}$mice and failed to pass stringent FDR threshold $(P=0.0047, \mathrm{FDR}=0.28)$. At P32, where we had increased power due to higher coverage and larger sample numbers and where Scnla expression is much higher in WT, Scnla was significantly lower in both heterozygous and homozygous $1 \mathrm{~b}$ deletion mice $(\mathrm{FDR}=$ 0.00028 and $1.97 \times 10$ [11], respectively; Fig. 6a, b, Additional file 1: Fig. S5a).

To compare transcripts arising from $1 \mathrm{a}$ and $1 \mathrm{~b}$ at P32, when Scn1a expression in WT brain is high, we measured the number of splice junction reads that linked the $1 \mathrm{a}$ and $1 \mathrm{~b}$ non-coding exons with the first Scn1a coding exon and the number of total reads that mapped unambiguously to 1a or 1b (Fig. 6c). As expected, splice junction and overlapping reads associated with mouse $1 \mathrm{~b}$ were reduced in $1 \mathrm{~b}^{+/-}$mice and abolished in $1 \mathrm{~b}^{-/-}$ mice (Fig. 6d, Additional file 1: Fig. S5b). Mouse 1a splice junction and overlapping reads appeared reduced in $1 \mathrm{~b}^{-1-}$ mice, though there were relatively low numbers of reads mapping to these intervals (Fig. $6 \mathrm{~d}$ top, Additional file 1: Fig. S5b left). In contrast, 1a-associated reads in heterozygous $1 \mathrm{~b}$ deletion carriers were increased (Fig. $6 \mathrm{~d}$ bottom, Additional file 1: Fig. S5b right). The increased 1a transcripts present in the $1 \mathrm{~b}^{+/-}$, but not the $1 \mathrm{~b}^{-1-}$ mice, is consistent with trans compensation by increased expression from the second Scn1a allele, but not with compensation of the deleted $1 \mathrm{~b}$ in cis via increased 1a usage. The change in total Scn1a reads from RNA-seq at P32 (Fig. 6d) was stronger than identified in adult brain tissues via qRT-PCR and $\mathrm{Na}_{\mathrm{V}} 1.1$ Western blot. Our findings suggest decreases in RNA and protein levels in $1 \mathrm{~b}$ deletion mice that are higher than predicted based on the proportion of Scn1a transcripts originating at $1 \mathrm{~b}$ observed here and in previous work [30].

We tested for differential expression across 15589, 14631, and 15002 genes that were robustly expressed in the P7, P32 heterozygous comparison, and P32 homozygous comparison RNA-seq datasets, respectively (RPKM values in Additional file 6: Table S5-7). No genes flanking Scn1a showed consistent robust differential expression (DE) in $1 \mathrm{~b}^{+/-}$and $1 \mathrm{~b}^{-/-}$mice at P7 or P32, indicating that the major regulatory effects of the deleted $S c n 1 a 1 b$ interval are specific to Scn1a expression (Additional file 1: Fig. S5a). At P7, we identified 21 mostly downregulated DE genes in $1 \mathrm{~b}^{+/-}$carriers and 47 downregulated and 61 upregulated $\mathrm{DE}$ genes in $1 \mathrm{~b}^{-1-}$ mice meeting an FDR $<0.05$ threshold (Additional file 6: Table S8, S9). The small effect of $1 \mathrm{~b}$ deletion on differential gene expression at P7 is consistent with the low expression and non-essential role of Scn1a in early postnatal development [75]. Later in development, P32 heterozygous $1 b$ deletion was associated with $223 \mathrm{DE}$ genes (175 downregulated, 48 upregulated) at $\mathrm{FDR}<0.05$ (Fig. 6e, Additional file 6: Table S10). Homozygous $1 b$ deletion carriers exhibited much stronger transcriptional impact, with a total of 723 DE genes (337 downregulated, 386 upregulated) DE at FDR $<0.05$ (Fig. 6f, Additional file 6: Table S11). Volcano plots that show $\log 2$ fold change effect sizes and significance values for $\mathrm{DE}$ genes in $1 \mathrm{~b}$ deletion mice shown in Fig. 6e, f. Gene set enrichment analysis of Gene Ontology (GO) found general synaptic signaling and function were enriched among downregulated DE genes in P32 heterozygous carriers, with no terms passing FDR $<0.05$ criteria for upregulated genes. In P32 homozygous $1 b$ carriers, enriched terms for neuron development and differentiation were associated with upregulated $\mathrm{DE}$ genes while synaptic signaling and mature neuronal function terms were enriched among downregulated DE genes (Fig. 6g). Heterozygous and homozygous $1 b$ deletion mutants shared 104 DE genes (Additional file 1: Fig. S5c), which were primarily downregulated and enriched for synaptic and differentiation terms (Additional file 1: Fig. S5d).

\section{Discussion}

The majority of functional studies of alternative promoters have been on genes where the multiple alternative TSSs are predicted to have discrete cell-type or tissue-specific activity [6-9]. However, recent studies of TSS usage and promoter interactions suggest a model where alternative promoters interact physically and are co-active in the same cells [12-14]. In these situations, it 
is largely unknown what the requirement for individual TSS and associated regulatory DNA may be. Here we focus on one specific putative non-canonical diseaserelevant alternative promoter, a 3-kb evolutionarily conserved DNA region including the previously described Scn1a 1b TSS. We show that full deletion of this interval from the mouse genome causes significant decrease in Scnla expression and $\mathrm{Na}_{\mathrm{V}} 1.1$ protein and results in spontaneous seizures and high developmental lethality with significant cognitive and behavioral deficits in surviving mice. While phenotypes were less severe in heterozygous $1 \mathrm{~b}^{+/-}$mice, presence of temperature and PTZ-induced behavioral seizures and elevated observations of epileptiform indices in EEG in these mice indicate a milder phenotype with relevance to SCN1Aassociated epilepsies [76-78]. Our results define $1 \mathrm{~b}$ as an essential disease-relevant $S c n 1 a$ regulatory region and show that loss of regulatory DNA associated with a noncanonical TSS can have a surprisingly strong and translationally relevant phenotypic impact.

There are multiple possible explanations for the observed strong impact of loss of the $1 \mathrm{~b}$ interval on Scn1a expression. First, $1 \mathrm{a}$ and $1 \mathrm{~b}$ isoforms may indeed be discretely regulated, but previous measures of $1 \mathrm{~b}$ originating transcripts must have significantly underestimated the actual contribution of $1 \mathrm{~b}$ transcripts to Scn1a expression. However, there is no evidence that earlier studies were incorrect and our estimates of Scn1a overall and $1 \mathrm{a}$ and $1 \mathrm{~b}$ RNA-seq read frequency in $1 \mathrm{~b}$ deletion mice do not support this simple model. Alternatively, the 1b TSS could have increased activity earlier in development or 1b-associated regulatory DNA activity could also be required for 1a transcription. These models are both plausible and consistent with our results. Considering the frequency of promoter-promoter interaction and reported common co-expression of alterative TSSs in single neurons, many brain genes could share similar regulatory structure as Scn1a. Our findings are consistent with models suggesting regulatory DNA at putative alternative promoters and associated regulatory sequences contributes to transcriptional activation across interacting TSSs. Further experiments are needed to resolve the specific cellular, molecular, and developmental function and potential co-dependence of the $1 \mathrm{a}$ and $1 \mathrm{~b}$ intervals and associated transcripts, and studies of other genes are needed to test if this phenomenon is widespread. Our findings represent initial insights into the essential regulatory roles of non-canonical promoters even when such TSSs produce mRNA encoding identical amino acid products.

Annotation of the genome has led to major gains in understanding transcriptional wiring, yet it has been surprisingly difficult to predict the sufficiency and necessity of specific regulatory elements, even those expected to be critical based on comparative and functional genomics $[3,10,79]$. Knockout mouse models have been a gold standard for testing the phenotypic consequences of mutations, and recent efforts deleting non-coding DNA have provided critical insights into the role of regulatory DNA [79-82]. Here, we used CRISPR/Cas9-mediated deletion to assess the role of the evolutionarily conserved $1 \mathrm{~b}$ interval on higher-order neurological phenotypes in mice. Homozygous $1 \mathrm{~b}$ deletion caused spontaneous seizures and behavioral deficits and had a strong impact on survival, demonstrating the essential nature of the deleted interval. Further studies are needed to define the minimal and core nucleotides within the $1 \mathrm{~b}$ interval and to define proteins that bind and participate in regulation. In addition, similar functional studies of other Scn1a regulatory DNA elements, and specifically of the 1a region, are necessary to determine which regulatory DNA regions are necessary and sufficient for expression in the brain.

Heterozygous loss of the $1 \mathrm{~b}$ interval appears to have a less severe impact compared to truncating Scn1a mutations, which are sufficient to reduce survival and cause behavioral and cognitive deficits relevant to DS and NDD in mice $[20,26]$. It is possible that phenotypes are milder in heterozygous $1 \mathrm{~b}$ deletion mice in this study compared to other Scn1a mouse models due to differences in genetic background or environment. In a review of Scn1a $a^{+-}$mouse models of Dravet syndrome [83], it was noted that those bred on a $6 \mathrm{~N}$ background were more susceptible to hyperthermia-induced seizures, yet had milder spontaneous seizures and improved survival rates relative to $6 \mathrm{~J}$ crosses. DS-model mice bred on 129/ SvJ genetic background have a higher threshold for thermally induced seizures, no cognitive impairments, and reduced rates of premature death [84]. The $1 \mathrm{~b}$ deletion mouse line was generated on a $\mathrm{C} 57 \mathrm{BL} / 6 \mathrm{~N}$ background and thus it is possible that phenotypes are milder due to this compared to if they were bred with C57BL/6J. However, there is also evidence that the milder phenotypes in $1 \mathrm{~b}$ deletion mice relative to Scn1a coding loss-offunction mutants is due to the different impacts on Scn1a dosage. Previously reported phenotypes of mice harboring heterozygous DS-associated Scnla truncating mutations are similar to or less severe than homozygous $1 \mathrm{~b}$ deletion phenotype identified here, suggesting stronger phenotypic impact in line with haploinsufficiency is produced by the more severe reduction in Scn1a expression caused by homozygous $1 \mathrm{~b}$ deletion. In support of this, the P32 homozygous DE signatures of downregulated synaptic expression and upregulated expression of earlier neuronal differentiation and maturation genes are consistent with previous data on Scnla truncating mutants [85]. Notably, these DE results could be driven by either developmental changes or reflect seizure 
pathology in $1 \mathrm{~b}$ deletion mice [85]. Further studies of $1 \mathrm{~b}$ deletion and Scn1a coding mutant mouse lines on the same genetic background will be needed to directly compare phenotype severity associated with $1 \mathrm{~b}$ deletion.

While we did not identify spontaneous behavioral seizures or corroborated behavioral phenotypes in heterozygous $1 \mathrm{~b}$ deletion mice, our characterization of $1 \mathrm{~b}^{+/-}$mice showed general epilepsy relevance. Heterozygous $1 \mathrm{~b}$ deletion mice exhibited spontaneous spike trains and abnormal EEG spectral bandwidths. In particular, the EEG results with increased spike trains observed $1 \mathrm{~b}^{+/-}$mice are indicative of general seizure relevance. It is likely that the increased spike events at baseline are associated with susceptibility to thermally induced seizures seen in $1 \mathrm{~b}^{+/-}$mice. At $41.5^{\circ} \mathrm{C}$, the temperature of seizure onset is higher than those observed for global Scn $1 a^{+/-}$mice $\left(38.5 \pm 0.2^{\circ} \mathrm{C}\right)$ [86] and hippocampal $\mathrm{Na}_{\mathrm{V}} 1.1$ deletion mice $\left(40.3 \pm 0.2^{\circ} \mathrm{C}\right)$ [74]. There are neurodevelopmental disorder genetic models where spontaneous behavioral seizures are not seen in mice while they are in humans [87-89]. As female $1 \mathrm{~b}^{+/-}$failed to efficiently reproduce, it is possible that milder but still DSrelevant behavioral and cognitive deficits are present in heterozygous $1 \mathrm{~b}$ deletion mice. The degree to which $1 \mathrm{~b}$ deletion is directly relevant to DS will require further studies. Regardless, our findings show the relevance of this novel Scn1a regulatory deletion mouse line to SCN1A-associated epilepsy.

The EEG spectral phenotypes in heterozygous 1b deletion mice overlap with other neurodevelopmental disorder and epilepsy models, and represent a potential translational biomarker for future investigation. Elevated delta spectral power is a biomarker of Angelman syndrome (AS) [90] and elevated beta spectral power is posited to be a biomarker of Dup15q syndrome [91, 92]. These disorders are of interest as there are co-occurring features with DS and epilepsy. AS and Dup15q both have high rates of seizures, cognitive disruption, and comorbid diagnosis with autism. Neural signatures in EEG by power bands can be similarly measured in both rodents and humans, and thus our findings have translational relevance [76-78]. Analysis of spike-firing and oscillatory activity during rewarded trials in touchscreen assays have recently been described in detail [93]. Given the behavioral deficits in cognitive function and firing activity identified here, future studies investigating behavioral outcomes and neurophysiological signals are warranted and will shed light on relationship between $1 \mathrm{~b}$ deletion, EEG spectral phenotypes, and behavior.

SCN1A-associated epilepsies, including DS, remain difficult to treat as conventional sodium channel blockers are usually ineffective and may even exacerbate the disease $[29,94]$. Precision therapies that rescue $\mathrm{Na}_{V} 1.1$ haploinsufficiency in relevant cell types would be preferred to ameliorate symptoms and reduce side effects compared to more globally acting therapies. Using CRIS $\mathrm{PR} / \mathrm{dCas} 9$ induction, we increased SCN1A expression in HEK293 cells by targeting the $1 \mathrm{~b}$ region. Application of a similar synthetic transcriptional activation therapeutic strategy has shown exciting promise in vivo in mice, where a dCas9-based activator combined with locusspecific guide RNA delivered to hypothalamus was capable of rescuing obesity phenotypes in $\operatorname{Sim} 1$ and $M c 4 r$ heterozygous mutant mice [95]. dCas9-VP160 activation of Scn1a 1b, but not 1a, by a single sgRNA was able to enhance Scn1a expression in P19 cells [96]. Delivery of the guide and dCas9-VP64 via AAV intracerebroventricular injections to forebrain GABAergic interneurons in a model of Dravet syndrome ameliorated hyperthermiainduced seizures [96]. Our data demonstrates that $1 \mathrm{~b}$ is an essential and important regulator of Scn1a expression and highlights a potential target for epigenomic intervention in SCN1A-related epilepsies. Studies characterizing the regulatory DNA at disease-relevant loci, as we have done here with the Scn1a 1b region, will be required to properly design therapies using targeted expression rescue.

\section{Conclusions}

The work here on the Scn1a 1b regulatory region contributes to functional dissection of the regulatory wiring of a major epilepsy risk gene. Our findings show that Scn1a 1b regulatory deletion mice represent a general epilepsy-relevant model that will be valuable for understanding the relationship between Scn1a dosage and neurological phenotypes in a genetic preclinical model. Our study justifies increased focus on non-coding regulatory DNA in genetic screening of DS and epilepsy patients, and highlights the need for more in-depth functional studies of regulatory DNA elements in general and specifically in haploinsufficiency-associated disorders.

\section{Abbreviations \\ AS: Angelman syndrome; DE: Differential expression; DS: Dravet syndrome; EEG: Electroencephalogram; GWAS: Genome-wide association study; IF: Immunofluorescence; NDD: Neurodevelopmental disorder; PFC: Prefrontal cortex; PND: Postnatal day; PTM: Post-translational modification; \\ PTZ: Pentylenetetrazole; PV: Parvalbumin; SUDEP: Sudden unexpected death in epilepsy; TAD: Topological associated domain; TSS: Transcription start site; UTR: Untranslated region; VIP: Vasoactive intestinal peptide; WT: Wildtype}

\section{Supplementary Information}

Supplementary information accompanies this paper at https://doi.org/10. 1186/s13073-021-00884-0.

Additional file 1: Supplementary Figures. Figure S1. Tissue and brain regional differences in chromatin conformation. Figure S2. Western blots of Nav1.1 (250 kDa) and $\beta$-actin (45 kDa) proteins in P29-32 brain lysates, membrane and cytoplasmic fractions ran separately. Figure S3. 
Immunofluorescent analysis of sagittal sections of P28 mice. Figure S4 Seizure severity following Pentylenetetrazole (PTZ) administration in C57BL6/N mice. Figure S5. Differential gene expression with Scnla $1 b$ deletion in P32 hippocampus.

Additional file 2:. Table S1. Expected Mendelian ratios and observed number of pups born.

Additional file 3:. Table S2. Summary of measures of general health and development in wildtype, heterozygous and homozygous $1 \mathrm{~b}$ deletion mice.

Additional file 4:. Table S3. Summary of the battery of behavioral tests. Additional file 5:. Table S4. Lack of sex difference between wildtype, $1 \mathrm{~b}^{+/-}$and $1 \mathrm{~b}^{-/-}$mice in behavioral assays.

Additional file 6: Table S5-11. Table S5. RPKM values for P7 samples. Table S6. RPKM values for P32 $1 \mathrm{~b}^{+/-}$samples. Table S7. RPKM values for P32 $1 \mathrm{~b}^{-/-}$samples. Table S8. Differentially expressed genes between WT and $1 \mathrm{~b}^{+/-}$mice at P7. Table S9. Differentially expressed genes between $W T$ and $1 b^{-1-}$ mice at P7. Table S10. Differentially expressed genes between $\mathrm{WT}$ and $1 \mathrm{~b}^{+/-}$mice at P32. Table S11. Differentially expressed genes between $\mathrm{WT}$ and $1 \mathrm{~b}^{-1-}$ mice at P3.

\section{Acknowledgements}

Sequencing was performed at the UC Berkeley and UC Davis DNA cores.

\section{Authors' contributions}

$J \mathrm{LH}$ and $\mathrm{AA}$ are listed as joint first authors, as each led major components of the study. JLH, AA, NAC, TS, AAW, RCP, LSF, JC, JLS, and ASN designed the experiments and analyses. JLH, AA, NAC, TS, IZ, SM, TAF, AN, DQ, MS, EK, SA, $J C, A G, J L, C P C, L A P, A V$, and DED performed experiments. AA, NAC, and TAF carried out mouse behavior. LSF, AAW, and ASN performed and interpreted transcriptomic analysis. JLH, IZ, SM, AN, DQ, SA, MS, and JC ran cell culture experiments. JLH, AA, NAC, JLS, and ASN drafted the manuscript. All authors contributed to the revisions. The author(s) read and approved the final manuscript.

\section{Funding}

This work was supported by funds from the Dravet Syndrome Foundation, Simons Foundation Autism Research Initiative and by NIGMS R35 GM119831. L.S.-F. was supported by the UC Davis Floyd and Mary Schwall Fellowship in Medical Research and by grant number T32-GM008799 from NIGMS-NIH. A.A.W. was supported by Training Grant number T32-GM007377 from NIHNIGMS and F31 MH119789-01. R.C.P. was supported by a Science Without Borders Fellowship from CNPq (Brazil). A.V., L.A.P., and D.E.D. were supported by National Institutes of Health grants R24HL123879, U01DE024427, R01HG003988, U54HG006997, and UM1HL098166. Research conducted the E.O. Lawrence Berkeley National Laboratory was performed under the Department of Energy Contract DE-AC02-05CH11231, University of California. We also thank Heather Boyle at the MIND Institute for her diligence and assistance with the mouse colonies. This work was supported by generous funding from the NIH R01NS097808 (JLS, NAC, AA) and the MIND Institute's Intellectual and Developmental Disabilities Resource Center (HD079125, PI Abbeduto).

\section{Availability of data and materials}

Transcriptomic datasets generated for this study are available via the Gene Expression Omnibus (GEO) archive under accessions GSE169481 www.ncbi nlm.nih.gov/bioproject/PRJNA716688 [97] and GSE169485 www.ncbi.nlm.nih. gov/bioproject/PRJNA716683 [98]. Differential Hi-C comparisons used GEO accession GSE87112, www.ncbi.nlm.nih.gov/bioproject/PRJNA343608 [39]. ATAC-seq datasets from human brain used GSE96949, https://www.ncbi.nlm. nih.gov/bioproject/PRJNA380200 [42]. ATAC-seq datasets from mouse brain used GSE63137, https://www.ncbi.nlm.nih.gov/bioproject/PRJNA266828 [43]. Roadmap Epigenomics Consortium data are available at https://egg2.wustl. edu/roadmap/web_portal/.

\section{Declarations}

Ethics approval and consent to participate

All mouse studies were approved by the Institutional Animal Care and Use Committees (IACUC) at the University of California Davis and the Lawrence Berkeley National Laboratory.

\section{Consent for publication}

Not applicable.

\section{Competing interests}

The authors declare that they have no competing interests.

\section{Author details}

${ }^{1}$ Department of Psychiatry and Behavioral Sciences, University of California, Davis, Davis, CA, USA. ${ }^{2}$ Department of Neurobiology, Physiology and Behavior, University of California, Davis, Davis, CA, USA. ${ }^{3}$ MIND Institute and Department of Psychiatry and Behavioral Sciences, UC Davis School of Medicine, Sacramento, CA, USA. ${ }^{4}$ Environmental Genomics and Systems Biology Division, Lawrence Berkeley National Laboratory, Berkeley, CA, USA. ${ }^{5}$ U.S. Department of Energy Joint Genome Institute, Walnut Creek, CA, USA. ${ }^{6}$ Comparative Biochemistry Program, University of California, Berkeley, Berkeley, CA, USA. ${ }^{7}$ School of Natural Sciences, University of California, Merced, CA, USA.

Received: 23 December 2020 Accepted: 6 April 2021

Published online: 26 April 2021

\section{References}

1. Landry J-R, Mager DL, Wilhelm BT. Complex controls: the role of alternative promoters in mammalian genomes. Trends Genet. 2003;19(11):640-8. https://doi.org/10.1016/j.tig.2003.09.014.

2. Forrest $A R R$, et al. A promoter-level mammalian expression atlas. Nature. 2014;507(7493):462-70. https://doi.org/10.1038/nature13182.

3. Carninci P, Kasukawa T, Katayama S, Gough J, Frith MC, Maeda N, Oyama R, Ravasi T, Lenhard B, Wells C, Kodzius R, Shimokawa K, Bajic VB, Brenner SE, Batalov S, Forrest AR, Zavolan M, Davis MJ, Wilming LG, Aidinis V, Allen JE, Ambesi-Impiombato A, Apweiler R, Aturaliya RN, Bailey TL, Bansal M, Baxter L, Beisel KW, Bersano T, Bono H, Chalk AM, Chiu KP, Choudhary V, Christoffels A, Clutterbuck DR, Crowe ML, Dalla E, Dalrymple BP, de Bono B, Della Gatta G, di Bernardo D, Down T, Engstrom P, Fagiolini M, Faulkner G, Fletcher CF, Fukushima T, Furuno M, Futaki S, Gariboldi M, GeorgiiHemming P, Gingeras TR, Gojobori T, Green RE, Gustincich S, Harbers M, Hayashi Y, Hensch TK, Hirokawa N, Hill D, Huminiecki L, lacono M, Ikeo K, Iwama A, Ishikawa T, Jakt M, Kanapin A, Katoh M, Kawasawa Y, Kelso J, Kitamura H, Kitano H, Kollias G, Krishnan SP, Kruger A, Kummerfeld SK, Kurochkin IV, Lareau LF, Lazarevic D, Lipovich L, Liu J, Liuni S, McWilliam S, Madan Babu M, Madera M, Marchionni L, Matsuda H, Matsuzawa S, Miki H, Mignone F, Miyake S, Morris K, Mottagui-Tabar S, Mulder N, Nakano N, Nakauchi H, Ng P, Nilsson R, Nishiguchi S, Nishikawa S, Nori F, Ohara O, Okazaki Y, Orlando V, Pang KC, Pavan WJ, Pavesi G, Pesole G, Petrovsky N, Piazza S, Reed J, Reid JF, Ring BZ, Ringwald M, Rost B, Ruan Y, Salzberg SL, Sandelin A, Schneider C, Schönbach C, Sekiguchi K, Semple CA, Seno S, Sessa L, Sheng Y, Shibata Y, Shimada H, Shimada K, Silva D, Sinclair B, Sperling S, Stupka E, Sugiura K, Sultana R, Takenaka Y, Taki K, Tammoja K, Tan SL, Tang S, Taylor MS, Tegner J, Teichmann SA, Ueda HR, van Nimwegen E, Verardo R, Wei CL, Yagi K, Yamanishi H, Zabarovsky E, Zhu S, Zimmer A, Hide W, Bult C, Grimmond SM, Teasdale RD, Liu ET, Brusic V, Quackenbush J, Wahlestedt C, Mattick JS, Hume DA, Kai C, Sasaki D, Tomaru Y, Fukuda S, Kanamori-Katayama M, Suzuki M, Aoki J, Arakawa T, lida J, Imamura K, Itoh M, Kato T, Kawaji H, Kawagashira N, Kawashima T, Kojima M, Kondo S, Konno H, Nakano K, Ninomiya N, Nishio T, Okada M, Plessy C, Shibata K, Shiraki T, Suzuki S, Tagami M, Waki K, Watahiki A, Okamura-Oho Y, Suzuki H, Kawai J, Hayashizaki Y, FANTOM Consortium, RIKEN Genome Exploration Research Group and Genome Science Group (Genome Network Project Core Group). The transcriptional landscape of the mammalian genome. Science. 2005;309(5740):1559-63. https://doi.org/10.1126/ science.1112014.

4. Yamashita R, Sathira NP, Kanai A, Tanimoto K, Arauchi T, Tanaka Y, Hashimoto SI, Sugano S, Nakai K, Suzuki Y. Genome-wide characterization of 
transcriptional start sites in humans by integrative transcriptome analysis. Genome Res. 2011;21(5):775-89. https://doi.org/10.1101/gr.110254.110.

5. Davuluri RV, Suzuki Y, Sugano S, Plass C, Huang THM. The functional consequences of alternative promoter use in mammalian genomes. Trends Genet. 2008;24(4):167-77. https://doi.org/10.1016/j.tig.2008.01.008.

6. Kimura K, Wakamatsu A, Suzuki Y, Ota T, Nishikawa T, Yamashita R, Yamamoto J, Sekine M, Tsuritani K, Wakaguri H, Ishii S, Sugiyama T, Saito K, Isono Y, Irie R, Kushida N, Yoneyama T, Otsuka R, Kanda K, Yokoi T, Kondo H, Wagatsuma M, Murakawa K, Ishida S, Ishibashi T, Takahashi-Fujii A, Tanase T, Nagai K, Kikuchi H, Nakai K, Isogai T, Sugano S. Diversification of transcriptional modulation: large-scale identification and characterization of putative alternative promoters of human genes. Genome Res. 2006;16(1): 55-65. https://doi.org/10.1101/gr.4039406.

7. de Klerk, E. \& 't Hoen, P. A. C. Alternative mRNA transcription, processing, and translation: insights from RNA sequencing. Trends Genet. 31, 128-39 (2015).

8. Tzvetkov MV, Meineke C, Oetjen E, Hirsch-Ernst K, Brockmöller J. Tissuespecific alternative promoters of the serotonin receptor gene HTR3B in human brain and intestine. Gene. 2007;386(1-2):52-62. https://doi.org/10.101 6/j.gene.2006.08.002

9. Reyes A, Huber W. Alternative start and termination sites of transcription drive most transcript isoform differences across human tissues. Nucleic Acids Res. 2018;46(2):582-92. https://doi.org/10.1093/nar/gkx1165.

10. Kim TH, Barrera LO, Zheng M, Qu C, Singer MA, Richmond TA, Wu Y, Green RD, Ren B. A high-resolution map of active promoters in the human genome. Nature. 2005;436(7052):876-80. https://doi.org/10.1038/nature03877.

11. Sandelin A, Carninci P, Lenhard B, Ponjavic J, Hayashizaki Y, Hume DA. Mammalian RNA polymerase II core promoters: insights from genome-wide studies. Nat Rev Genet. 2007:8(6):424-36. https://doi.org/10.1038/nrg2026.

12. Karlsson K, Lönnerberg $P$, Linnarsson S. Alternative TSSs are co-regulated in single cells in the mouse brain. Mol Syst Biol. 2017;13(5):930. https://doi. org/10.15252/msb.20167374.

13. Li G, Ruan X, Auerbach RK, Sandhu KS, Zheng M, Wang P, Poh HM, Goh Y, Lim J, Zhang J, Sim HS, Peh SQ, Mulawadi FH, Ong CT, Orlov YL, Hong S, Zhang Z, Landt S, Raha D, Euskirchen G, Wei CL, Ge W, Wang H, Davis C, Fisher-Aylor Kl, Mortazavi A, Gerstein M, Gingeras T, Wold B, Sun Y, Fullwood MJ, Cheung E, Liu E, Sung WK, Snyder M, Ruan Y. Extensive promoter-centered chromatin interactions provide a topological basis for transcription regulation. Cell. 2012;148(1-2):84-98. https://doi.org/10.1016/j.cell.2011.12.014.

14. Zhang Y, Wong CH, Birnbaum RY, Li G, Favaro R, Ngan CY, Lim J, Tai E, Poh HM, Wong E, Mulawadi FH, Sung WK, Nicolis S, Ahituv N, Ruan Y, Wei CL. Chromatin connectivity maps reveal dynamic promoter-enhancer longrange associations. Nature. 2013;504(7479):306-10. https://doi.org/10.1038/ nature12716.

15. Claes LR, Deprez L, Suls A, Baets J, Smets K, van Dyck T, Deconinck T, Jordanova A, de Jonghe P. The SCN1A variant database: a novel research and diagnostic tool. Hum Mutat. 2009;30(10):E904-20. https://doi.org/10.1 002/humu.21083.

16. Lossin C. A catalog of SCN1A variants. Brain and Development. 2009;31(2): 114-30. https://doi.org/10.1016/j.braindev.2008.07.011.

17. Parihar R, Ganesh S. The SCN1A gene variants and epileptic encephalopathies. J Hum Genet. 2013;58(9):573-80. https://doi.org/10.1038/ jhg.2013.77.

18. McArdle EJ, Kunic JD, George AL Jr. Novel SCN1A frameshift mutation with absence of truncated Nav1.1 protein in severe myoclonic epilepsy of infancy. Am J Med Genet. 2008;A 146A:2421-3.

19. Meng $H$, Xu HQ, Yu L, Lin GW, He N, Su T, Shi YW, Li B, Wang J, Liu XR, Tang B, Long YS, Yi YH, Liao WP. The SCN1A mutation database: updating information and analysis of the relationships among genotype, functional alteration, and phenotype. Hum Mutat. 2015;36(6):573-80. https://doi.org/1 0.1002/humu.22782.

20. Yu FH, Mantegazza M, Westenbroek RE, Robbins CA, Kalume F, Burton KA, Spain WJ, McKnight GS, Scheuer T, Catterall WA. Reduced sodium current in GABAergic interneurons in a mouse model of severe myoclonic epilepsy in infancy. Nat Neurosci. 2006;9(9):1142-9. https://doi.org/10.1038/nn1754.

21. Ogiwara I, et al. Nav1.1 haploinsufficiency in excitatory neurons ameliorates seizure-associated sudden death in a mouse model of Dravet syndrome. Hum Mol Genet. 2013;22:4784-804.

22. Miller AR, Hawkins NA, McCollom CE, Kearney JA. Mapping genetic modifiers of survival in a mouse model of Dravet syndrome. Genes Brain Behav. 2014;13(2):163-72. https://doi.org/10.1111/gbb.12099.
23. Tai C, Abe Y, Westenbroek RE, Scheuer T, Catterall WA. Impaired excitability of somatostatin- and parvalbumin-expressing cortical interneurons in a mouse model of Dravet syndrome. Proc Natl Acad Sci. 2014;111(30):E313948. https://doi.org/10.1073/pnas.1411131111.

24. Dutton SB, Makinson CD, Papale LA, Shankar A, Balakrishnan B, Nakazawa K, Escayg A. Preferential inactivation of Scn1a in parvalbumin interneurons increases seizure susceptibility. Neurobiol Dis. 2013;49:211-20. https://doi. org/10.1016/j.nbd.2012.08.012.

25. Cheah CS, et al. Specific deletion of NaV1.1 sodium channels in inhibitory interneurons causes seizures and premature death in a mouse model of Dravet syndrome. Proc Natl Acad Sci USA. 2012;109:14646-51.

26. Ogiwara I, Miyamoto H, Morita N, Atapour N, Mazaki E, Inoue I, Takeuchi T, Itohara S, Yanagawa Y, Obata K, Furuichi T, Hensch TK, Yamakawa K. Nav1.1 localizes to axons of parvalbumin-positive inhibitory interneurons: a circuit basis for epileptic seizures in mice carrying an Scn1a gene mutation. J Neurosci. 2007; 27(22):5903-14. https://doi.org/10.1523/JNEUROSCl.5270-06.2007.

27. Kalume F. Sudden unexpected death in Dravet syndrome: respiratory and other physiological dysfunctions. Respir Physiol Neurobiol. 2013;189(2):3248. https://doi.org/10.1016/j.resp.2013.06.026.

28. Shmuely S, Sisodiya SM, Gunning WB, Sander JW, Thijs RD. Mortality in Dravet syndrome: a review. Epilepsy Behav. 2016;64(Pt A):69-74. https://doi. org/10.1016/j.yebeh.2016.09.007.

29. Wirrell EC. Treatment of Dravet syndrome. Can J Neurol Sci. 2016;43(S3): S13-8. https://doi.org/10.1017/cjn.2016.249.

30. Martin MS, Tang B, Ta N, Escayg A. Characterization of 5' untranslated regions of the voltage-gated sodium channels SCN1A, SCN2A, and SCN3A and identification of cis-conserved noncoding sequences. Genomics. 2007; 90(2):225-35. https://doi.org/10.1016/j.ygeno.2007.04.006.

31. Long $Y$-S, et al. Identification of the promoter region and the $5^{\prime}$ untranslated exons of the human voltage-gated sodium channel $\mathrm{Na}$ v 1.1 gene ( SCN1A ) and enhancement of gene expression by the 5'untranslated exons. J Neurosci Res. 2008;86:3375-81.

32. Lonsdale J, Thomas J, Salvatore M, Phillips R, Lo E, Shad S, Hasz R, Walters G, Garcia F, Young N, Foster B, Moser M, Karasik E, Gillard B, Ramsey K, Sullivan S, Bridge J, Magazine H, Syron J, Fleming J, Siminoff L, Traino H, Mosavel M, Barker L, Jewell S, Rohrer D, Maxim D, Filkins D, Harbach P, Cortadillo E, Berghuis B, Turner L, Hudson E, Feenstra K, Sobin L, Robb J, Branton P, Korzeniewski G, Shive C, Tabor D, Qi L, Groch K, Nampally S, Buia S, Zimmerman A, Smith A, Burges R, Robinson K, Valentino K, Bradbury D, Cosentino M, Diaz-Mayoral N, Kennedy M, Engel T, Williams P, Erickson K, Ardlie K, Winckler W, Getz G, DeLuca D, MacArthur D, Kellis M, Thomson A, Young T, Gelfand E, Donovan M, Meng Y, Grant G, Mash D, Marcus Y, Basile M, Liu J, Zhu J, Tu Z, Cox NJ, Nicolae DL, Gamazon ER, Im HK, Konkashbaev A, Pritchard J, Stevens M, Flutre T, Wen X, Dermitzakis ET, Lappalainen T, Guigo R, Monlong J, Sammeth M, Koller D, Battle A, Mostafavi S, McCarthy M, Rivas M, Maller J, Rusyn I, Nobel A, Wright F, Shabalin A, Feolo M, Sharopova N, Sturcke A, Paschal J, Anderson JM, Wilder EL, Derr LK, Green ED, Struewing JP, Temple G, Volpi S, Boyer JT, Thomson EJ, Guyer MS, Ng C, Abdallah A, Colantuoni D, Insel TR, Koester SE, Little AR, Bender PK, Lehner T, Yao Y, Compton CC, Vaught JB, Sawyer S, Lockhart NC, Demchok J, Moore HF. The Genotype-Tissue Expression (GTEx) project. Nat Genet. 2013; 45(6):580-5. https://doi.org/10.1038/ng.2653.

33. International League Against Epilepsy Consortium on Complex Epilepsies. Electronic address: epilepsy-austin@unimelb.edu.au. Genetic determinants of common epilepsies: a meta-analysis of genome-wide association studies. Lancet Neurol. 13, 893-903 (2014).

34. ILAE, T. I. L. A. E. C. on C. E. Genome-wide mega-analysis identifies 16 loci and highlights diverse biological mechanisms in the common epilepsies. Nat Commun. 2018. 9; 5269.

35. Gao Q-W, Hua LD, Wang J, Fan CX, Deng WY, Li B, Bian WJ, Shao CX, He N, Zhou P, Liao WP, Shi YW. A point mutation in SCN1A 5' genomic region decreases the promoter activity and is associated with mild epilepsy and seizure aggravation induced by antiepileptic drug. Mol Neurobiol. 2017; 54(4):2428-34. https://doi.org/10.1007/s12035-016-9800-y.

36. Nakayama T, Ogiwara I, Ito K, Kaneda M, Mazaki E, Osaka H, Ohtani H, Inoue Y, Fujiwara T, Uematsu M, Haginoya K, Tsuchiya S, Yamakawa K. Deletions of SCN1A 5' genomic region with promoter activity in Dravet syndrome. Hum Mutat. 2010;31(7):820-9. https://doi.org/10.1002/humu.21275.

37. Lange IM, et al. Influence of common SCN1A promoter variants on the severity of SCN1A -related phenotypes. Mol Genet Genomic Med. 2019:e727. https://doi.org/10.1002/mgg3.727. 
38. PsychENCODE Consortium, S, et al. The PsychENCODE project. Nat Neurosci. 2015;18:1707-12

39. Schmitt AD, Hu M, Jung I, Xu Z, Qiu Y, Tan CL, Li Y, Lin S, Lin Y, Barr CL, Ren B. A compendium of chromatin contact maps reveals spatially active regions in the human genome. Cell Rep. 2016;17(8):2042-59. https://doi. org/10.1016/j.celrep.2016.10.061.

40. Roadmap Epigenomics Consortium, A, et al. Integrative analysis of 111 reference human epigenomes. Nature. 2015;518:317-30.

41. Kent WJ, Sugnet CW, Furey TS, Roskin KM, Pringle TH, Zahler AM, H. D UCSC Genome browser Available at: http://genome.ucsc.edu. Accessed 05 April 2021.

42. Fullard JF, Hauberg ME, Bendl J, Egervari G, Cirnaru MD, Reach SM, Motl J, Ehrlich ME, Hurd YL, Roussos P. An atlas of chromatin accessibility in the adult human brain. Genome Res. 2018;28(8):1243-52. https://doi.org/10.11 01/gr.232488.117.

43. Mo A, Mukamel EA, Davis FP, Luo C, Henry GL, Picard S, Urich MA, Nery JR, Sejnowski TJ, Lister R, Eddy SR, Ecker JR, Nathans J. Epigenomic signatures of neuronal diversity in the mammalian brain. Neuron. 2015;86(6):1369-84. https://doi.org/10.1016/..neuron.2015.05.018.

44. Mali $P$, et al. RNA-guided human genome engineering via Cas9. Science. 2013;339:823-6.

45. Gompers AL, Su-Feher L, Ellegood J, Copping NA, Riyadh MA, Stradleigh TW, Pride MC, Schaffler MD, Wade AA, Catta-Preta R, Zdilar I, Louis S, Kaushik G, Mannion BJ, Plajzer-Frick I, Afzal V, Visel A, Pennacchio LA, Dickel DE, Lerch JP, Crawley JN, Zarbalis KS, Silverman JL, Nord AS. Germline Chd8 haploinsufficiency alters brain development in mouse. Nat Neurosci. 2017;20(8):1062-73. https://doi.org/10.1038/nn.4592.

46. Dobin A, Davis CA, Schlesinger F, Drenkow J, Zaleski C, Jha S, Batut P, Chaisson M, Gingeras TR. STAR: ultrafast universal RNA-seq aligner. Bioinformatics. 2013;29(1):15-21. https://doi.org/10.1093/bioinformatics/ bts635.

47. Liao Y, Smyth GK, Shi W. FeatureCounts: an efficient general purpose program for assigning sequence reads to genomic features. Bioinformatics. 2014;30(7):923-30. https://doi.org/10.1093/bioinformatics/btt656

48. Wang L, Wang S, Li W. RSeQC: quality control of RNA-seq experiments. Bioinformatics. 2012;28(16):2184-5. https://doi.org/10.1093/bioinformatics/bts356.

49. MD, R., DJ, M. \& GKS. edgeR: a Bioconductor package for differential expression analysis of digital gene expression data. Bioinformatics 26, 139140 (2009).

50. Adhikari A, Copping NA, Onaga B, Pride MC, Coulson RL, Yang M, Yasui DH, LaSalle JM, Silverman JL. Cognitive deficits in the Snord116 deletion mouse model for Prader-Willi syndrome. Neurobiol Learn Mem. 2018;165:106874. https://doi.org/10.1016/j.nlm.2018.05.011.

51. Fox WM. Reflex-ontogeny and behavioural development of the mouse. Anim Behav. 1965;13(2-3):234-IN5. https://doi.org/10.1016/0003-3472 (65) $90041-2$.

52. Copping NA, et al. Neuronal overexpression of Ube3a isoform 2 causes behavioral impairments and neuroanatomical pathology relevant to $15 q 11$. 2-q13.3 duplication syndrome. Hum Mol Genet. 2017;26:3995-4010.

53. Flannery BM, Silverman JL, Bruun DA, Puhger KR, McCoy MR, Hammock BD, Crawley JN, Lein PJ. Behavioral assessment of NIH Swiss mice acutely intoxicated with tetramethylenedisulfotetramine. Neurotoxicol Teratol. 2015; 47:36-45. https://doi.org/10.1016/..ntt.2014.10.008.

54. Yang M, Lewis FC, Sarvi MS, Foley GM, Crawley JN. 16p11.2 Deletion mice display cognitive deficits in touchscreen learning and novelty recognition tasks. Learn Mem. 2015;22:622-32.

55. Brooks SP, Pask T, Jones L, Dunnett SB. Behavioural profiles of inbred mouse strains used as transgenic backgrounds. I: motor tests. Genes Brain Behav. 2004;3(4):206-15. https://doi.org/10.1111/j.1601-183X.2004.00072.x.

56. Carter RJ, Morton J, Dunnett SB. Motor coordination and balance in rodents. Curr Protoc Neurosci. 2001;15:8.12.1-8.12.14.

57. Vogel Ciernia A, Pride MC, Durbin-Johnson B, Noronha A, Chang A, Yasui $\mathrm{DH}$, Crawley JN, LaSalle JM. Early motor phenotype detection in a female mouse model of Rett syndrome is improved by cross-fostering. Hum Mol Genet. 2017;26(10):1839-54. https://doi.org/10.1093/hmg/ddx087.

58. Yang M, Bozdagi O, Scattoni ML, Wohr M, Roullet FI, Katz AM, Abrams DN, Kalikhman D, Simon H, Woldeyohannes L, Zhang JY, Harris MJ, Saxena R, Silverman JL, Buxbaum JD, Crawley JN. Reduced excitatory neurotransmission and mild autism-relevant phenotypes in adolescent Shank3 null mutant mice. J Neurosci. 2012;32(19):6525-41. https://doi.org/1 0.1523/JNEUROSCI.6107-11.2012.
59. Silverman JL, Turner SM, Barkan CL, Tolu SS, Saxena R, Hung AY, Sheng M, Crawley JN. Sociability and motor functions in Shank1 mutant mice. Brain Res. 2011;1380:120-37. https://doi.org/10.1016/j.brainres.2010.09.026.

60. Silverman JL, Pride MC, Hayes JE, Puhger KR, Butler-Struben HM, Baker $\mathrm{S}$, Crawley JN. GABAB receptor agonist R-baclofen reverses social deficits and reduces repetitive behavior in two mouse models of autism. Neuropsychopharmacology. 2015;40(9):2228-39. https://doi.org/10.1038/ npp.2015.66.

61. Dhamne SC, Silverman JL, Super CE, Lammers SHT, Hameed MQ, Modi ME, Copping NA, Pride MC, Smith DG, Rotenberg A, Crawley JN, Sahin M. Replicable in vivo physiological and behavioral phenotypes of the Shank3B null mutant mouse model of autism. Mol Autism. 2017;8(1):26. https://doi. org/10.1186/s13229-017-0142-z.

62. Copping NA, Berg EL, Foley GM, Schaffler MD, Onaga BL, Buscher N, Silverman JL, Yang M. Touchscreen learning deficits and normal social approach behavior in the Shank3B model of Phelan-McDermid syndrome and autism. Neuroscience. 2017:345:155-65. https://doi.org/10.1016/j. neuroscience.2016.05.016.

63. Papaleo F, Silverman JL, Aney J, Tian Q, Barkan CL, Chadman KK, Crawley JN. Working memory deficits, increased anxiety-like traits, and seizure susceptibility in BDNF overexpressing mice. Learn Mem. 2011;18(8):534-44. https://doi.org/10.1101//m.2213711.

64. Wang $D$, et al. Comprehensive functional genomic resource and integrative model for the human brain. Science. 2018;362:eaat8464.

65. Hilton IB, D'Ippolito AM, Vockley CM, Thakore PI, Crawford GE, Reddy TE, Gersbach CA. Epigenome editing by a CRISPR-Cas9-based acetyltransferase activates genes from promoters and enhancers. Nat Biotechnol. 2015;33(5): 510-7. https://doi.org/10.1038/nbt.3199.

66. Cheah CS, Westenbroek RE, Roden WH, Kalume F, Oakley JC, Jansen LA, Catterall WA. Correlations in timing of sodium channel expression, epilepsy, and sudden death in Dravet syndrome. Channels. 2013;7(6):468-72. https:// doi.org/10.4161/chan.26023.

67. Dravet C. The core Dravet syndrome phenotype. Epilepsia. 2011;52:3-9. https://doi.org/10.1111/j.1528-1167.2011.02994.x.

68. Escayg A, Goldin AL. Sodium channel SCN1A and epilepsy: mutations and mechanisms. Epilepsia. 2010;51(9):1650-8. https://doi.org/10.1111/j.1528-11 67.2010.02640.x.

69. Copping NA, Adhikari A, Petkova SP, JS. Genetic backgrounds have unique seizure response profiles and behavioral outcomes following convulsant administration. Epilepsy Behav. 2019;101(Pt A):106547. https://doi.org/10.101 6/j.yebeh.2019.106547. Epub 2019 Nov 4.

70. Genton P, Velizarova R, Dravet C. Dravet syndrome: the long-term outcome. Epilepsia. 2011;52:44-9. https://doi.org/10.1111/j.1528-1167.2011.03001.x.

71. Rubinstein M, Han S, Tai C, Westenbroek RE, Hunker A, Scheuer T, Catterall WA. Dissecting the phenotypes of Dravet syndrome by gene deletion. Brain. 2015;138(8):2219-33. https://doi.org/10.1093/brain/awv142.

72. Silverman JL, Yang M, Lord C, Crawley JN. Behavioural phenotyping assays for mouse models of autism. Nat Rev Neurosci. 2010;11(7):490-502. https:// doi.org/10.1038/nrn2851.

73. Sukoff Rizzo SJ, Silverman JL. Methodological considerations for optimizing and validating behavioral assays. Curr Protoc Mouse Biol. 2016;6(4):364-79. https://doi.org/10.1002/cpmo.17.

74. Stein RE, Kaplan JS, Li J, Catterall WA. Hippocampal deletion of NaV1.1 channels in mice causes thermal seizures and cognitive deficit characteristic of Dravet Syndrome. Proc Natl Acad Sci USA. 2019; https://doi.org/10.1073/ pnas. 1906833116.

75. Cheah CS, et al. Channels correlations in timing of sodium channel expression, epilepsy, and sudden death in Dravet syndrome. Channels. 2013:7:468-72. https://doi.org/10.4161/chan.26023.

76. Featherstone RE, McMullen MF, Ward KR, Bang J, Xiao J, Siegel SJ. EEG biomarkers of target engagement, therapeutic effect, and disease process. Ann N Y Acad Sci. 2015;1344(1):12-26. https://doi.org/10.1111/nyas.12745.

77. Modi ME, Sahin M. Translational use of event-related potentials to assess circuit integrity in ASD. Nat Rev Neurol. 2017;13(3):160-70. https://doi.org/1 0.1038/nrneurol.2017.15.

78. Dickinson A, DiStefano C, Lin YY, Scheffler AW, Senturk D, Jeste SS. Interhemispheric alpha-band hypoconnectivity in children with autism spectrum disorder. Behav Brain Res. 2018;348:227-34. https://doi.org/10.101 6/j.bbr.2018.04.026.

79. Cunningham TJ, Lancman JJ, Berenguer M, Dong PDS, Duester G. Genomic knockout of two presumed forelimb Tbx5 enhancers reveals they are 
nonessential for limb development. Cell Rep. 2018;23(11):3146-51. https:// doi.org/10.1016/j.celrep.2018.05.052.

80. Dickel $\mathrm{DE}$, et al. Ultraconserved enhancers are required for normal development. Cell. 2018;172:491-499.e15.

81. Hewitt SC, Lierz SL, Garcia M, Hamilton KJ, Gruzdev A, Grimm SA, Lydon JP, Demayo FJ, Korach KS. A distal super enhancer mediates estrogen-dependent mouse uterine-specific gene transcription of lgf1 (insulin-like growth factor 1). J Biol Chem. 2019;294(25):9746-59. https://doi.org/10.1074/jbc.RA119.008759.

82. Johnson KR, Gagnon LH, Tian C, Longo-Guess CM, Low BE, Wiles MV, Kiernan AE. Deletion of a long-range Dlx5 enhancer disrupts inner ear development in mice. Genetics. 2018;208(3):1165-79. https://doi.org/10.1 534/genetics.117.300447.

83. Kang SK, Hawkins NA, Kearney JA. C57BL/6J and C57BL/6N substrains differentially influence phenotype severity in the $\mathrm{Scnla}^{+/-}$mouse model of Dravet syndrome. Epilepsia Open. 2018:4:epi4.12287.

84. Rubinstein M, Westenbroek RE, Yu FH, Jones CJ, Scheuer T, Catterall WA. Genetic background modulates impaired excitability of inhibitory neurons in a mouse model of Dravet syndrome. Neurobiol Dis. 2015;73:106-17. https://doi.org/10.1016/j.nbd.2014.09.017.

85. Hawkins NA, Calhoun JD, Huffman AM, Kearney JA. Gene expression profiling in a mouse model of Dravet syndrome. Exp Neurol. 2019;311:24756. https://doi.org/10.1016/j.expneurol.2018.10.010.

86. Oakley JC, Kalume F, Yu FH, Scheuer T, Catterall WA. Temperature- and agedependent seizures in a mouse model of severe myoclonic epilepsy in infancy. Proc Natl Acad Sci U S A. 2009;106(10):3994-9. https://doi.org/10.1 073/pnas.0813330106.

87. Terzic B, Cui Y, Edmondson AC, Tang S, Sarmiento N, Zaitseva D, Marsh ED Coulter DA, Zhou Z. X-linked cellular mosaicism underlies age-dependent occurrence of seizure-like events in mouse models of CDKL5 deficiency disorder. Neurobiol Dis. 2021;148:105176. https://doi.org/10.1016/j.nbd.202 0.105176 .

88. Fallah MS, Eubanks JH. Seizures in mouse models of rare neurodevelopmental disorders. Neuroscience. 2020;445:50-68. https://doi. org/10.1016/j.neuroscience.2020.01.041.

89. Colic S, Wither RG, Zhang L, Eubanks JH, Bardakjian BL. Characterization of seizure-like events recorded in vivo in a mouse model of Rett syndrome. Neural Netw. 2013:46:109-15. https://doi.org/10.1016/j.neunet.2013.05.002.

90. Sidorov MS, Deck GM, Dolatshahi M, Thibert RL, Bird LM, Chu CJ, Philpot BD. Delta rhythmicity is a reliable EEG biomarker in Angelman syndrome: a parallel mouse and human analysis. J Neurodev Disord. 2017;9(1):17. https:// doi.org/10.1186/s11689-017-9195-8.

91. Frohlich J, Reiter LT, Saravanapandian V, DiStefano C, Huberty S, Hyde C, Chamberlain S, Bearden CE, Golshani P, Irimia A, Olsen RW, Hipp JF, Jeste SS. Mechanisms underlying the EEG biomarker in Dup15q syndrome. Mol. Autism. 2019;10(1):29. https://doi.org/10.1186/s13229-019-0280-6.

92. Frohlich J, Senturk D, Saravanapandian V, Golshani P, Reiter LT, Sankar R, Thibert RL, DiStefano C, Huberty S, Cook EH, Jeste SS. A quantitative electrophysiological biomarker of duplication 15q11.2-q13.1 syndrome. Plos One. 2016;11(e0167179) https://doi.org/10.1371/journal.pone.0167179.

93. Marquardt K, Sigdel R, Brigman JL. Touch-screen visual reversal learning is mediated by value encoding and signal propagation in the orbitofrontal cortex. Neurobiol Learn Mem. 2017;139:179-88. https://doi.org/10.1016/j. nlm.2017.01.006.

94. Guerrini R, Dravet C, Genton P, Belmonte A, Kaminska A, Dulac+ O. Lamotrigine and seizure aggravation in severe myoclonic epilepsy. Epilepsia. 1998;39(5):508-12. https://doi.org/10.1111/j.1528-1157.1998.tb01413.x.

95. Matharu N, et al. CRISPR-mediated activation of a promoter or enhancer rescues obesity caused by haploinsufficiency. Science. 2019;363:eaau0629.

96. Colasante $\mathrm{G}$, et al. dCas9-based Scn1a gene activation restores inhibitory interneuron excitability and attenuates seizures in Dravet syndrome mice. Mol Ther. 2019:28:235-53.

97. Haigh, J. L. et al. Deletion of a non-canonical regulatory sequence causes loss of Scn1a expression and epileptic phenotypes in mice. GSE169481 Available at: www.ncbi.nIm.nih.gov/bioproject/PRJNA716688. Accessed 05 April 2021

98. Haigh, J. L. et al. Deletion of a non-canonical regulatory sequence causes loss of Scnla expression and epileptic phenotypes in mice. GSE169485 Available at: www.ncbinlm.nih.gov/bioproject/PRJNA716683. Accessed 05 April 2021.

\section{Publisher's Note}

Springer Nature remains neutral with regard to jurisdictional claims in published maps and institutional affiliations.

Ready to submit your research? Choose BMC and benefit from:

- fast, convenient online submission

- thorough peer review by experienced researchers in your field

- rapid publication on acceptance

- support for research data, including large and complex data types

- gold Open Access which fosters wider collaboration and increased citations

- maximum visibility for your research: over $100 \mathrm{M}$ website views per year

At BMC, research is always in progress.

Learn more biomedcentral.com/submissions 